\title{
Stem cells and fluid flow drive cyst formation in an invertebrate excretory organ
}

\author{
Hanh Thi-Kim Vu ${ }^{1,2}$, Jochen C Rink ${ }^{3}$, Sean A McKinney ${ }^{1}$, Melainia McClain ${ }^{1}$, \\ Naharajan Lakshmanaperumal ${ }^{3}$, Richard Alexander ${ }^{1}$, \\ Alejandro Sánchez Alvarado ${ }^{1,2,4 *}$
}

${ }^{1}$ Stowers Institute for Medical Research, Kansas City, United States; ${ }^{2}$ Department of Neurobiology and Anatomy, University of Utah, Salt Lake City, United States; ${ }^{3}$ Max Planck Institute of Molecular Cell Biology and Genetics, Dresden, Germany; ${ }^{4}$ Howard Hughes Medical Institute, Stowers Institute for Medical Research, Kansas City, United States

Abstract Cystic kidney diseases (CKDs) affect millions of people worldwide. The defining pathological features are fluid-filled cysts developing from nephric tubules due to defective flow sensing, cell proliferation and differentiation. The underlying molecular mechanisms, however, remain poorly understood, and the derived excretory systems of established invertebrate models (Caenorhabditis elegans and Drosophila melanogaster) are unsuitable to model CKDs. Systematic structure/function comparisons revealed that the combination of ultrafiltration and flow-associated filtrate modification that is central to CKD etiology is remarkably conserved between the planarian excretory system and the vertebrate nephron. Consistently, both RNA-mediated genetic interference (RNAi) of planarian orthologues of human CKD genes and inhibition of tubule flow led to tubular cystogenesis that share many features with vertebrate CKDs, suggesting deep mechanistic conservation. Our results demonstrate a common evolutionary origin of animal excretory systems and establish planarians as a novel and experimentally accessible invertebrate model for the study of human kidney pathologies.

*For correspondence: asa@ stowers.org

\section{Competing interests:}

See page 23

Funding: See page 23

Received: 10 March 2015

Accepted: 09 June 2015

Published: 09 June 2015

Reviewing editor: Yukiko $\mathrm{M}$ Yamashita, University of Michigan, United States

C) Copyright Thi-Kim Vu et al. This article is distributed under the terms of the Creative Commons Attribution License, which permits unrestricted use and redistribution provided that the original author and source are credited.
DOI: 10.7554/eLife.07405.001

\section{Introduction}

The vertebrate kidney plays a pivotal role in the maintenance of organismal homeostasis in the face of changing external and internal conditions. Its myriad individual functions, including the removal of metabolic waste products, regulation of ion concentrations and acid/base balance, are all tied to two basic physiological processes: (1) the pressure-driven ultra-filtration of blood plasma across the glomerulus, whereby molecular sieves prevent the passage of large macromolecules (e.g., plasma proteins); and (2) the subsequent modification of the resulting filtrate during its passage through the epithelial nephron tube (Ruppert and Smith, 1988; Ruppert, 1994). The parallel operation of many millions of glomerulus/nephron units allows formidable filtration rates, amounting to 170 liters of primary filtrate/day in a healthy human adult. In line with the pivotal homeostatic roles of the kidney, kidney diseases pose a serious health problem. The most common human kidney disorders are cystic kidney diseases (CKDs), affecting nearly 12 million people worldwide (Priolo and Henske, 2013). CKDs encompass a wide range of hereditary, developmental, and acquired conditions (Bisceglia et al., 2006), all of which share the pathological hallmark of fluid-filled cysts developing in the kidney. This has led to the suggestion that the molecular mechanisms causing cyst formation are similar, or at least, share a common pathway (Watnick and Germino, 2003). The molecular cloning of multiple 
eLife digest Millions of people around the world are affected by cystic kidney diseases, which are amongst the most common inherited genetic disorders. Throughout their life, people with these diseases develop fluid-filled cysts in their kidneys, which stop these organs from working properly and can eventually lead to organ failure.

Healthy kidneys perform many vital roles in the body, including removing waste products and keeping the concentration of salts in the blood in balance. These activities depend on the kidneys filtering the blood, and then reabsorbing useful chemicals from the filtered fluid as it passes through small tubes called tubules. Cysts disrupt both of these processes.

Mutations in many different genes can cause cystic kidney diseases. Many of these genes encode proteins that are involved in the formation of cilia: hair-like structures that project from some cell membranes. Cilia on the cells that line tubules are thought to bend in response to the flow of fluid and then generate signals that dampen cell proliferation. This would explain how the loss of cilia could cause too many cells to develop, which would lead to the formation of cysts. But many of the molecular details are missing from this explanation. Previous studies in mammals and simple model organisms (such as fruit flies and roundworms) have sought to fill in the gaps, but each model has its own limitations.

Now, Thi-Kim Vu et al. propose that a flat worm called a planarian could provide a new and experimentally accessible animal model to study cystic kidney diseases. These flat worms get rid of their waste products via an excretory system that consists of branched tubules that spread throughout the body. Thi-Kim Vu et al. found that, like the tubules in the kidney, these tubules filter and then reabsorb chemicals from body fluids. Moreover, these processes are performed in different parts of the tubules, exactly as they are in the tubules in kidneys.

The genome of a flat worm called Schmidtea mediterranea contains many genes that cause cysts to form when their equivalents are mutated in humans. Reducing the expression of these genes (and others that are involved in cilia formation) also caused cysts to form in the flat worms.

These findings indicate that it is likely that the excretory systems of different animals have a shared evolutionary history. If so, the findings support the idea that cilia in kidney tubules send signals in response to fluid flow that affect kidney-specific stem cells. They also suggest that problems with these signals could be at the core of some human cystic kidney diseases. One of the next challenges will be to identify these cilia-associated signals. Finally, given that studies involving thousands of flat worms can be carried out with minimal cost, the ultimate goal is to develop flat worms into a new model to discover and investigate genes linked to human kidney diseases. DOI: 10.7554/eLife.07405.002

CKD mutations and the realization that the affected genes all function at the primary cilia, basal bodies or centrosomes, has given rise to the ciliary hypothesis as a unifying disease mechanism of CKDs (Yoder et al., 2002; Mollet et alo, 2005; Fliegauf et alo, 2006). Accordingly, the primary cilia of tubule cells are thought to act as flow sensors, eliciting intracellular calcium fluxes through stretch sensitive polycystin channels in response to flow-driven bending (Praetorius and Spring, 2001, 2003; Nauli et al., 2003; Praetorius et al., 2004). These signals are thought to constitutively dampen cell proliferation, such that loss of filtrate flow or interruptions in the signal transduction process precipitate chronic overproliferation and consequently cyst formation (Deane and Ricardo, 2012). However, major mechanistic aspects of the ciliary hypothesis remain poorly understood, including the integration of the calcium signal with downstream transcriptional regulation of cell behavior (Wilson and Goilav, 2007; Uhlenhaut and Treier, 2008; Deane and Ricardo, 2012; Kotsis et alo, 2013), the extent by which cyst development can be understood as chronic activity of endogenous repair mechanisms (Deane and Ricardo, 2012), and the identity and origins of the ectopically overproliferating cells (Murer et al., 2002; Weimbs, 2007; Lodi et al., 2012). Further, these questions present an investigative challenge, given the poor experimental accessibility of the mammalian kidney as an internal and essential organ. The Xenopus pronephros and zebrafish pro- and mesonephric kidneys, therefore, are increasingly being explored as model systems for human kidney disease (Drummond, 2005; Ebarasi et al., 2011). Compounding this problem is the fact that it has not been possible to bring the full power of invertebrate models in solving fundamental cell biological 
processes to the analysis of human kidney disease (Igarashi, 2005; Dow and Romero, 2010). Both Caenorhabditis elegans and Drosophila melanogaster have highly derived excretory organs in which ultrafiltration is either entirely lacking (C. elegans; [Buechner, 2002]) or uncoupled from reabsorption/ secretion (D. melanogaster; [Dow and Romero, 2010]). Furthermore, the excretory cells of both organisms are lacking cilia as a further requirement for modeling CKDs. However, C. elegans or Drosophila are but two of the myriad invertebrate species and multiple studies have documented the existence of more complex excretory systems outside the Ecdysozoa (Ruppert and Smith, 1988). One such example is the excretory system of planarian flatworms. We and others have previously reported on intriguing similarities between planarian protonephridia and the vertebrate nephron (Rink et al., 2011; Scimone et al., 2011). Here, we carried out a systematic structure function comparison to systematically gauge the potential of planarian protonephridia as a model system for human kidney diseases. Our results demonstrate the structural coupling of cilia-driven ultrafiltration and filtrate modification in planarian protonephridia, as well as extensive topological homology of solute carrier expression domains with the vertebrate nephron. These structure/function homologies extend to common pathologies, including shared requirements of nephrin in the maintenance of the ultrafiltration barrier, and of nephrocystins in preventing the development of tubular cysts. Our results therefore establish planarian protonephridia as a novel and viable invertebrate model for studying human kidney development and diseases.

\section{Results}

\section{Protonephridia are ultrafiltration devices in planarian}

The planarian excretory system consists of branched epithelial tubules (protonephridia) distributed throughout the entire body plan (Figure 1A) (Rink et al., 2011). The barrel-shaped flame cells capping the proximal tubule (PT) ends have been proposed to act as unicellular ultrafiltration devices solely on the basis of morphological evidence (Figure 1B) (Wilhelmi, 1906; Wilson and Webster, 1974). To functionally test this premise, we adapted an assay previously used to demonstrate the ultrafiltration capacity of Drosophila nephrocytes (Weavers et al., 2009; Zhuang et al., 2009). We coinjected two inert and differentially labeled tracer molecules of different sizes into the anterior planarian mesenchyme (10 kDa and $500 \mathrm{kDa}$ molecular weight dextrans). Already at 2-hr post injection, we found robust tracer accumulation in protonephridia throughout the body, confirming their active role in extracellular fluid processing. Interestingly, only the small molecular weight tracer produced intense and continuous protonephridial labeling, whereas the large dextran displayed weak and patchy labeling (Figure $1 C, D$ ). Because the two tracer molecules in the injection mix carried equal numbers of fluorophores, the preferential accumulation of the small over the large dextran particles indicates molecular size filtration upon entry into the protonephridial system. We conclude from these experiments that planarian protonephridia, like vertebrate nephrons, combine ultrafiltration with filtrate modification in the same structure.

\section{Unexpected complexity of protonephridial tubules}

We next sought to investigate the filtrate modification capacities of the planarian protonephridial system. In the vertebrate nephron, the expression of a large number and diverse types of solute carrier (slc) transporters recovers essential molecules from the primary filtrate or secretes waste products into the tubule lumen (Landowski, 2008; Raciti et al., 2008). The known substrate specificity of slc families together with their restricted expression in specific nephron segments establishes a structure/function topology of filtrate modification processes along the nephron. Towards the dual goal of identifying and mapping solute modification processes in planarian protonephridia, we set out to identify, clone and expression-map all solute carriers in the planarian genome. A systematic sequence homology search of the planarian Schmidtea mediterranea genome identified 318 slc genes. Reciprocal BLAST analysis and sequence alignments revealed that $S$. mediterranea slcs represent 43 slc families (Figure 2-figure supplement 1, Figure 2-figure supplement 2, Figure 2-figure supplement 3, Figure 2-figure supplement 4, Figure 2-figure supplement 5, Figure 2-figure supplement 6, Figure 2-figure supplement 7, Supplementary file 1). Expression patterns of all slc genes were analyzed by in situ hybridization in intact asexual planarians. We obtained expression patterns for 287 genes in various tissues (Figure 2-figure supplement 8, Figure 2-figure supplement 9, Figure 2-figure supplement 10, Figure 2-figure supplement 11, Figure 2-figure supplement 12, 

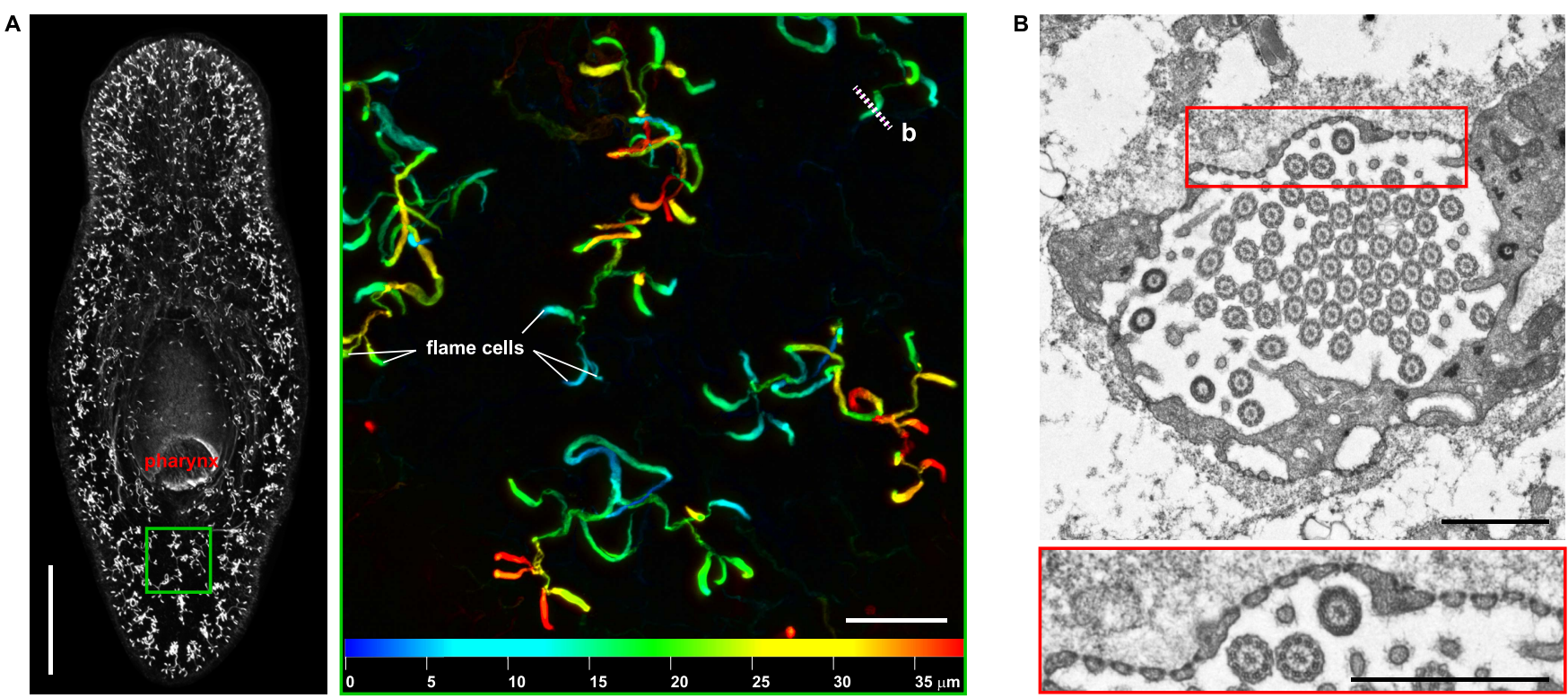

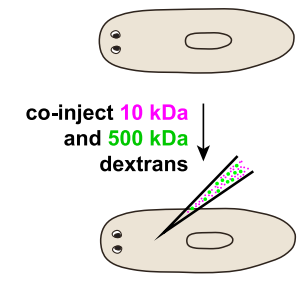

fix and image 2-hr after injection

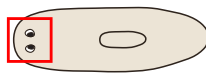

10 kDa Dextran
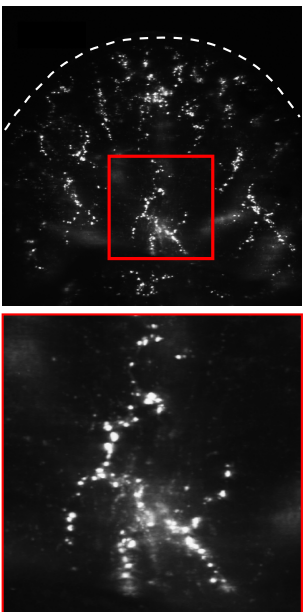

500 kDa Dextran
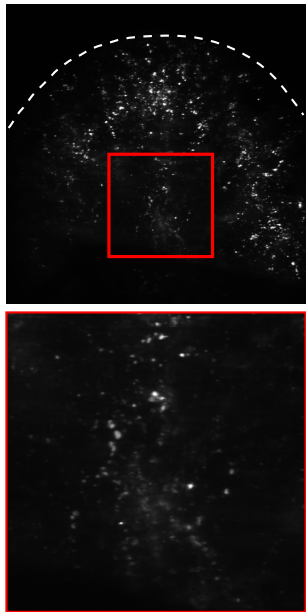
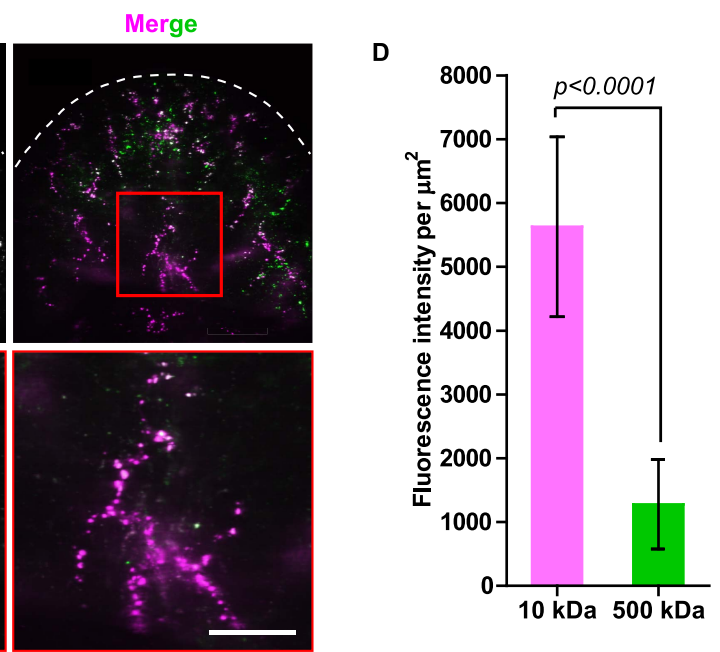

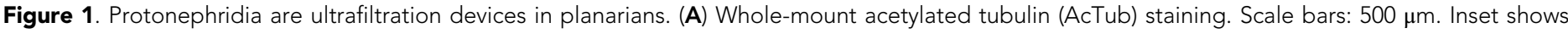

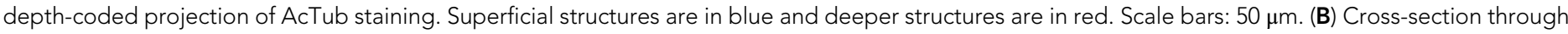

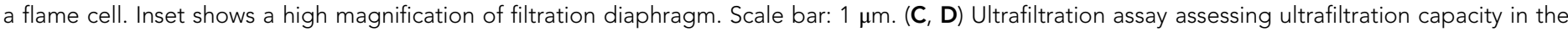

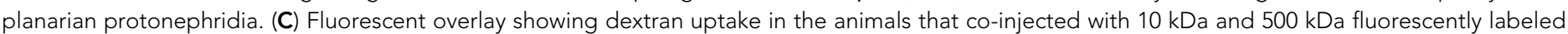

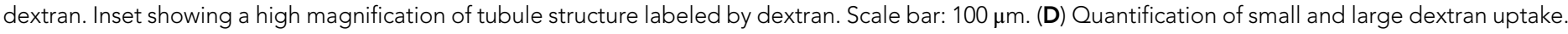
DOI: 10.7554/eLife.07405.003

Figure 2-figure supplement 13), with 49 of these displaying putative protonephridial expressions. The expression of such a large fraction of slc genes in protonephridial tubules already indicated a rich potential for solute modifications.

In order to establish a comprehensive structure-function map of protonephridia, we next mapped the expression domain of each protonephridial slc relative to two previously characterized markers (Figure 2A, top; Supplementary file 2): (1) acetylated tubulin (AcTub) antibody staining, which marks flame cells and the adjoining PT segment; and (2) Smed-CAVII-1, which is expressed in the adjacent distal tubule (DT) segment (Rink et al., 2011). Markers for the domain distal to CAVII-1 expression were not available at the beginning of this study. Fluorescent in situ hybridization (FISH) mapping of putative protonephridial slc genes against the two markers and general tubule anatomy 
(e.g., branched vs coiled PT segments) revealed a significantly greater complexity of protonephridial cell types than previously appreciated (Figure 2A; Figure 2-figure supplement 14, Figure 2-figure supplement 15, Figure 2-figure supplement 16, Figure 2-figure supplement 17, Figure 2-figure supplement 18, Figure 2-figure supplement 19, Figure 2-figure supplement 20). slc expression domains define at least three sub-domains within the PT (PT1, PT2, and PT3; Figure 2A-D) and the non-overlapping expression of representative slc genes in 3-color FISH experiments demonstrates the significance of the inferred PT subdivisions (Figure 2-figure supplement 14, Figure 2-figure supplement 15, Figure 2-figure supplement 16, Figure 2-figure supplement 17). Similarly, we found that slc expression domains divide the DT into 2 sub-domains (DT1 and DT2; Figure 2A,D-F; Figure 2-figure supplement 18F). Interestingly, the slc12a-4 expression domain extended beyond CAVII-1 expression, where it was co-expressed with a further cohort of 14 slc genes, including Smed-slc24a-3 (Figure 2A, G, Figure 2-figure supplement 19, [Scimone et al., 2011]). Together, these 14 slc genes therefore define the so far unknown continuation of protonephridia beyond the CAVII-1 expression domain, which for reasons detailed below we refer to as the 'Collecting Duct' (CD). Interestingly, CD marker expressing segments were exclusively located close to the dorsal body surface, supporting early reports suggesting that the protonephridial terminus was located in the dorsal epithelium (Wilhelmi, 1906). Consistently, sagittal sections revealed occasional $C D$ segments crossing the basement membrane and appearing to terminate in the single-layered outer epithelium (e.g., Smed-slc12a-1, Figure 2H). To confirm this finding, we performed electron microscopy (EM) on serial thin sections and succeeded in visualizing multiple examples of ducts connecting into the dorsal epithelium and opening directly to the exterior (Figure 21, Video 1). The presence of mitochondria and numerous small vesicles is ultrastructural characteristics of this region, similar to that of type B intercalated cells in the vertebrate CD.

For the first time, our results trace the complete course of protonephridial tubules from the ultrafiltrating flame cells as proximal entry point to their terminus in the dorsal epithelium. Further, our systematic mapping of expression domains of slc genes defined 6 molecularly distinct segments along the proximal-distal axis of protonephridia.

\section{Extensive functional homology between planarian protonephridia and vertebrate nephrons}

We next took advantage of our expression data and the known transport activities of slc families in vertebrates to infer possible functional specializations of these 6 protonephridial segments. Clustering a subset of slc genes with known substrate specificity by substrate class and site of expression revealed a striking segregation of similar transport activities into similar regions of the protonephridial tubule, indicating the functional specialization of different segments (Figure 3A, top). Because this subset of slc genes was intentionally chosen due to its known representation for transport activities of specific segments of the nephron (Raciti et al., 2008), this map afforded a basis for direct structure/ function comparisons with the vertebrate nephron. Constructing a similar map of slc expression in the rodent metanephros based on published data (Figure 3A, bottom; Supplementary file 3) revealed striking parallel: Not only is the sequence of slc family expression very similar along the filtrate flow axis, but almost all nephron segments have clearly identifiable homologous segments in protonephridia. In vertebrates, the PT is responsible for the reabsorption of more than $70 \%$ of filtered solutes from the primary urine, including inorganic/organic ions and vital nutrients (glucose, amino acids, and vitamins). The homologous slc expression of planarian PT1-3 and the preferential labeling of PT1-2 by injected dextran (Figure 3B) provide strong evidence that the proximal protonephridial segments are likewise primarily responsible for the recovery of filtered substances. The DT plays an important role in acid-base homeostasis by reabsorbing bicarbonates and secreting protons into the urine (Carraro-Lacroix and Malnic, 2010). The corresponding expression of bicarbonate (e.g., Smed-slc4a-6, Figure 2-figure supplement 18A) or proton transporters (e.g., $\mathrm{Na}^{+} / \mathrm{H}^{+}$ exchanger Smed-slc9a-3, Figure 2E) in DT1 and DT2 suggests a similar function of these protonephridial segments. Consistently, the RNAi knockdown of slc4a-6 caused a measurable acidification of the intercellular milieu (Figure 3C), supporting a functionally conserved role of DT1-2 in planarian $\mathrm{pH}$ homeostasis. Moreover, the vertebrate $\mathrm{CD}$ comprises distinct cortical and medullary segments and mediates the bulk of water recovery/urine concentration (Nielsen et al., 2002). The shared expression of the bicarbonate transporter Smed-s/c4a-7 and the ammonia transporter 

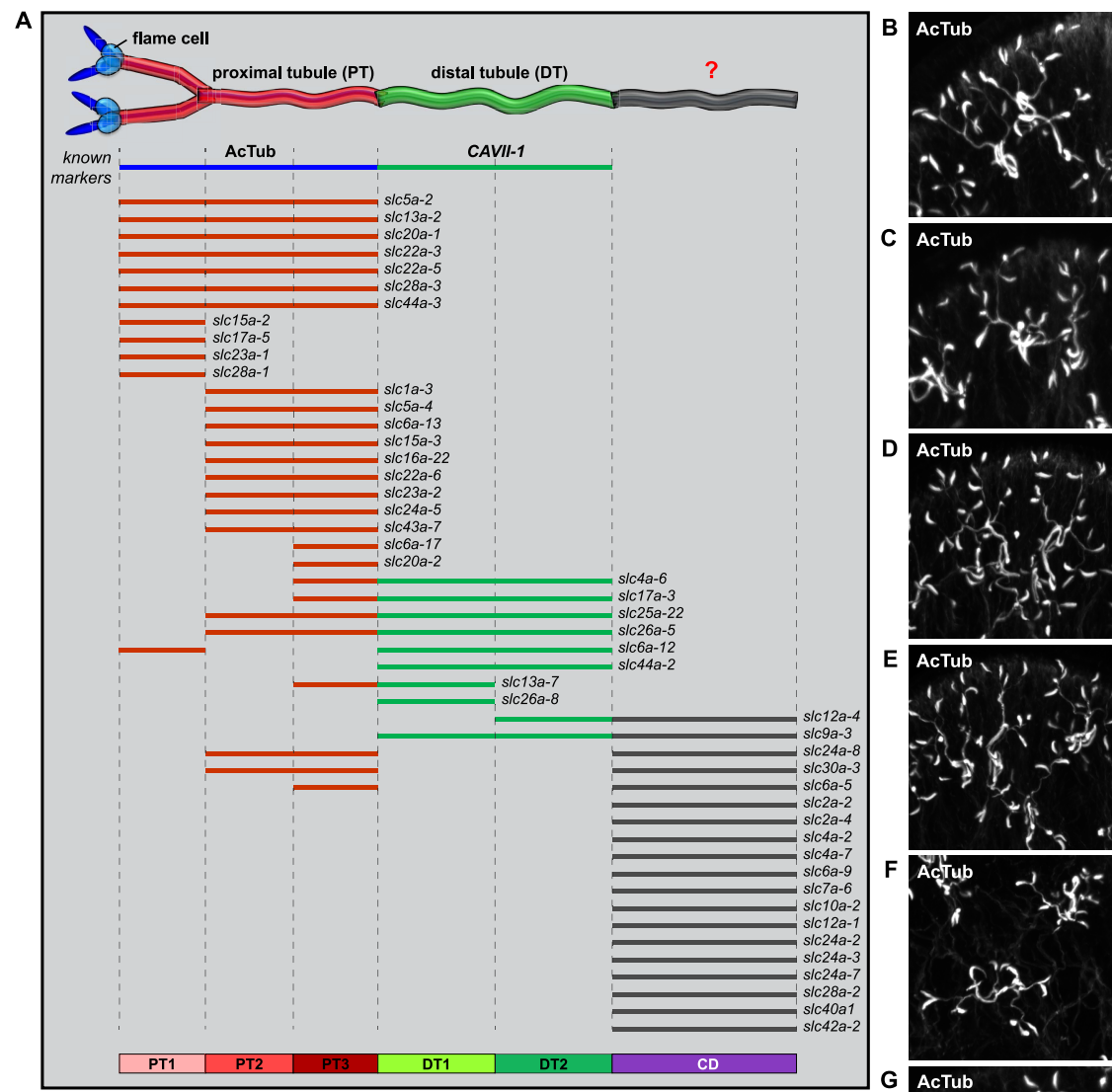

D
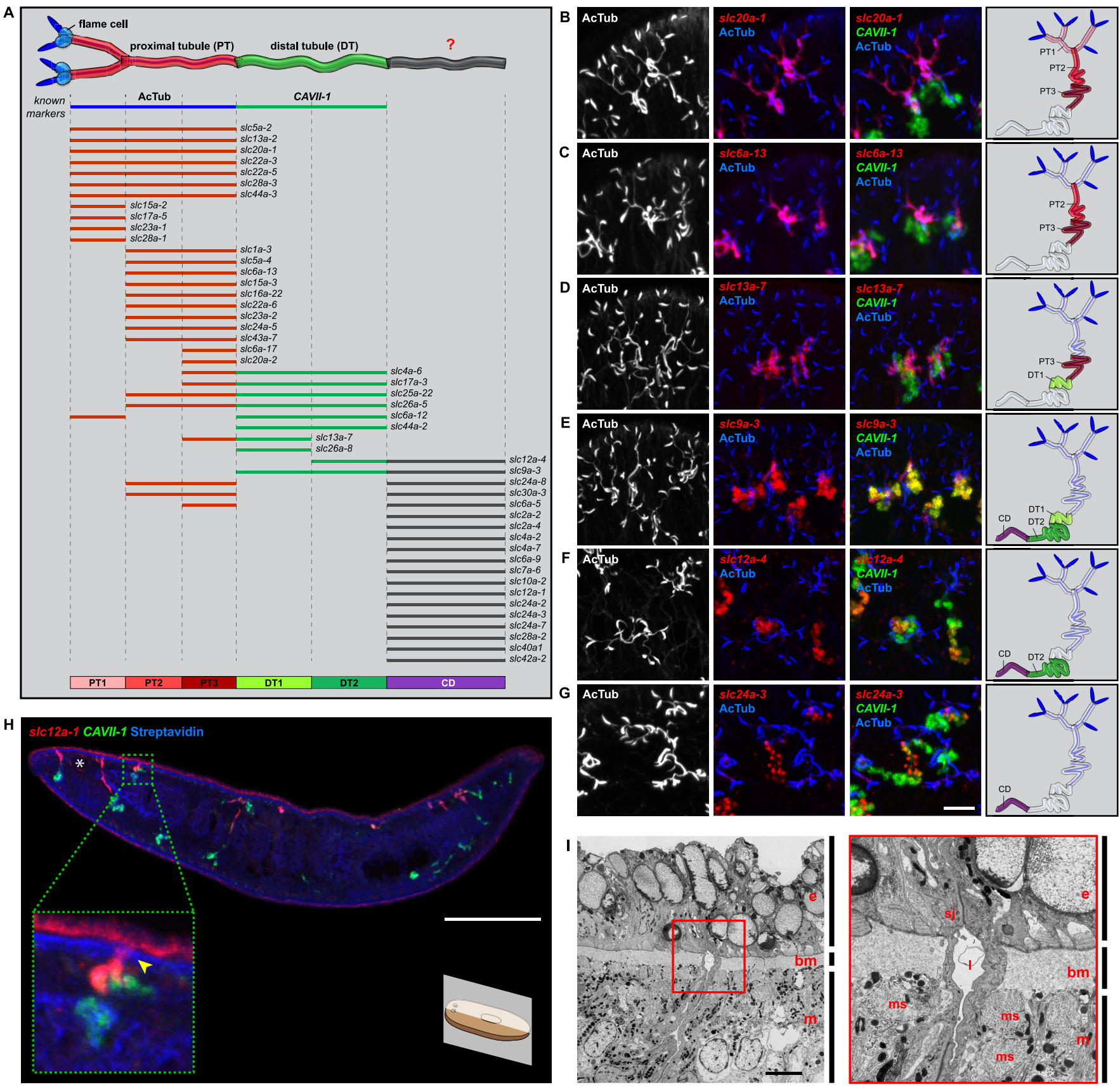

Figure 2. Unexpected complexity of protonephridial tubules is revealed by systematic gene expression mapping of slc genes along the protonephridial tubules. (A) Cartoon shows previous segmentation model of the protonephridial tubule and expression map of slc genes along the protonephridial tubule. (B-G) Representative images show expression domains of selected slc genes in (B) PT1, PT2 and PT3, (C) PT2 and PT3, (D) PT3, (E) DT1, DT2 and CD, (F) DT2 and CD and (G) CD. Fluorescent overlay of the indicated gene (red) with PT marker (AcTub) and distal tubule (DT) marker (CAVII-1). A colorcoded scheme of the protonephridial tubule at the end of each panel represents the expression domain of the indicated gene. Images are maximum projections of confocal Z-sections. Scale bars: $50 \mu \mathrm{m}$. (H) Longitudinal-section through a worm shows a dorsal-bias expression of slc12a-1. Fluorescent overlay of s/c12a-1 with DT marker (CAVII-1) and streptavidin (which labels the basement membrane of several planarian epithelial structures, including the outer epithelium). Inset shows a magnification of CD, visualized by slc12a-1, crossing the basement membrane of the dorsal epithelia. Yellow arrowhead, exterior opening of the CD. Scale bars: $200 \mu \mathrm{m}$. (I) TEM image shows CD connected to the dorsal epithelia. Inset shows a magnification of CD connected to the dorsal epithelia. e, epithelia; bm, basement membrane; m, mesenchyme; sj, septate junction; l, lumen; ms, muscle. Scale bars: $5 \mu$ m. DOI: 10.7554/eLife.07405.004

The following figure supplements are available for figure 2:

Figure 2. continued on next page 
Figure 2. Continued

Figure supplement 1. Solute carrier gene families in the planarian Schmidtea mediterranea. DOI: 10.7554/eLife.07405.005

Figure supplement 2. Schematic representation of phylogenetic clusters of $\boldsymbol{\gamma}$ - (A), $\delta$ - (B) groups of slcs and the Tim barrel- (C), IT- (D), Drug/Metabolite (E) transporter clans of slcs.

DOI: 10.7554/eLife.07405.006

Figure supplement 3. Schematic representation of phylogenetic clusters of $\alpha$-groups of slcs. DOI: 10.7554/eLife.07405.007

Figure supplement 4. Schematic representation of phylogenetic clusters of $\beta$-groups of slcs. DOI: 10.7554/eLife.07405.008

Figure supplement 5. Schematic representation of phylogenetic clusters of Smed-slc1a (A), Smed-slc5a (B), Smed-slc22a (C), Smed-slc6a (D). DOI: 10.7554/eLife.07405.009

Figure supplement 6. Schematic representation of phylogenetic clusters of Smed-slc4a (A), Smed-slc7a (B), Smed-slc12 (C), Smed-slc15 (D), Smed-slc20 (E), Smed-slc23 (F), Smed-slc26 (G).

DOI: 10.7554/eLife.07405.010

Figure supplement 7. Schematic representation of phylogenetic clusters of Smed-slc28 (A), Smed-slc30 (B), and Smed-slc42 (C). DOI: 10.7554/eLife.07405.011

Figure supplement 8. Expression patterns of slc genes that belong to solute carrier families 1-6 in an asexual strain of the planarian S. mediterranea. DOI: 10.7554/eLife.07405.012

Figure supplement 9. Expression patterns of slc genes that belong to solute carrier families 7-15 in an asexual strain of the planarian S. mediterranea. DOI: 10.7554/eLife.07405.013

Figure supplement 10. Expression patterns of slc genes that belong to solute carrier families 16-23 in an asexual strain of the planarian S. mediterranea. DOI: 10.7554/eLife.07405.014

Figure supplement 11. Expression patterns of slc genes that belong to solute carrier families 24-29 in an asexual strain of the planarian S. mediterranea. DOI: 10.7554/eLife.07405.015

Figure supplement 12. Expression patterns of slc genes that belong to solute carrier families 30-38 in an asexual strain of the planarian S. mediterranea. DOI: 10.7554/eLife.07405.016

Figure supplement 13. Expression patterns of slc genes that belong to solute carrier families $40-47$ in an asexual strain of the planarian S. mediterranea. DOI: 10.7554/eLife.07405.017

Figure supplement 14. Expression of slc genes in the PT.

DOI: 10.7554/eLife.07405.018

Figure supplement 15. Expression of slc genes in the PT1 segment of the PT.

DOI: 10.7554/eLife.07405.019

Figure supplement 16. Expression of slc genes in the PT2 and PT3 segments of the PT. DOI: 10.7554/eLife.07405.020

Figure supplement 17. Expression of slc genes in PT3 segment of the PT.

DOI: 10.7554/eLife.07405.021

Figure supplement 18. Expression of slc genes in the DT.

DOI: 10.7554/eLife.07405.022

Figure supplement 19. Expression of slc genes in the collecting duct.

DOI: 10.7554/eLife.07405.023

Figure supplement 20. Expression of slc genes weakly expressed in both proximal and DTs.

DOI: 10.7554/eLife.07405.024

Smed-slc42a-2 in the terminal segment (Figure 3A) supports a basal homology between the CD and the corresponding protonephridial segment, which is why we have chosen to adopt the vertebrate nomenclature. However, the large number of additional slc genes expressed in the protonephridial $\mathrm{CD}$ (Figure 2A) and the lack of aquaporin expression (not shown) suggest divergent functions.

The only nephron segment for which our analysis did not identify a protonephridial homologue was the intermediate tubule (IT). In terrestrial vertebrates, IT and CD have tightly linked functions in water conservation, whereby urea secretion by the IT establishes high extracellular solute concentrations that aid in water reabsorption from the CD (Pannabecker, 2012). As freshwater animals, planarian protonephridia have to clear, rather than conserve water, providing a compelling rationale for why specifically IT and CD are divergent. Such functional diversity of IT/CD segments is also observed in the pronephric kidneys of freshwater vertebrates, such as zebrafish (Wingert and Davidson, 2008). 


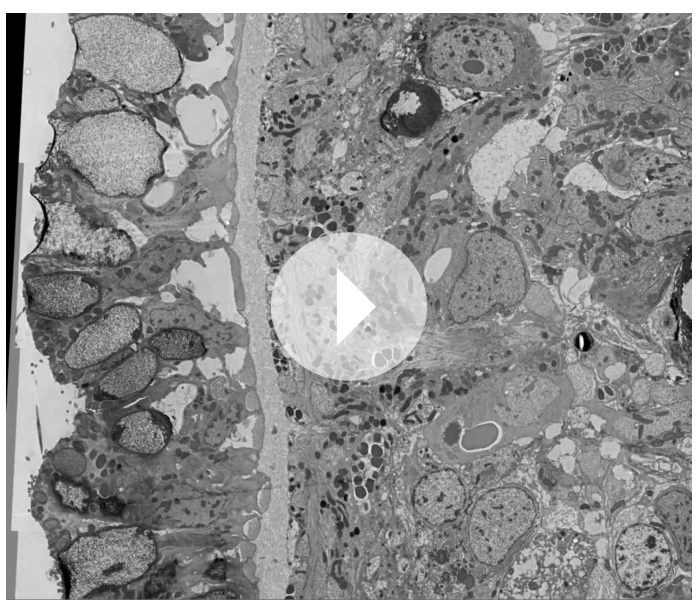

Video 1. Protonephridial collecting duct opens to the dorsal epithelia. Serial TEM images showing the protonephridial collecting duct connected to the dorsal epithelia.

DOI: 10.7554/eLife.07405.025
Altogether, our analyses reveal a striking structural and functional homology between the vertebrate nephron and the planarian protonephridium.

\section{Recapitulation of podocyte slitdiaphragm pathologies in flame cells}

We next asked whether the homologies between nephrons and protonephridia extend to common pathologies. The striking structural similarities between the ultrafiltration sites in the two systems, podocyte foot processes (Pavenstadt et al., 2003) and flame cell filtration barriers (Figure 1B) could reflect a requirement for common components. In humans, mutations in the large lgG-repeat transmembrane proteins NPHS1 and NEPH1 cause slit diaphragm loss by fusion of neighboring foot processes into a continuous cytoplasmic sheet (foot process effacement), resulting in proteinuria and edema (Kestila et al., 1998; Donoviel et al., 2001). Systematic sequence homology searches of the $S$. mediterranea genome identified 7 NPHS1 homologs and 3 NEPH homologs (Figure 4-figure supplement 1). of both genes produced strong bloating and partial clearing of body pigmentation (Figure $3 C$ ). Both phenotypes have previously been identified as characteristic hallmarks of tissue edema (Rink et al., 2011), thus providing a strong indication that the genes are required for the function of the planarian excretory system.

Because flame cell numbers appeared normal in both intact and regenerating animals (Figure 4-figure supplement 2), we examined the ultrastructure of the filtration diaphragm in NPHS1-6 and NEPH-3(RNAi) planarians. Wild type flame cells display slit-shaped 35-40 nm wide fenestrae that form between 90-150 nm wide foot processes (Figures 1B, 4D). Under RNAi knockdown of either NPHS1-6 or NEPH-3, the filtration diaphragm was completely absent and the foot processes underwent apparent effacement in both intact (Figure 4D, Videos 2, 3) and regenerating animals (Figure 4-figure supplement 3). The dextran injection assay confirmed the loss of ultrafiltration capability in NPHS1-6(RNAi) planarians, which displayed equal uptake of both small and large molecular tracer in the PT (Figure 4E,F). Why would the fusion of foot processes into a continuous sheet result in loss of filtration size selectively, rather than a general block of filtration? In human nephrotic syndrome patients, the loss of ultrafiltration capability in thought to occur as a consequence of podocyte detachment or apoptosis and subsequent filtrate leakage (Tojo and Kinugasa, 2012). However, many nephrotic syndrome patients present ultrafiltration deficiencies without podocyte detachment or loss (Furness et al., 1999; Lahdenkari et al., 2004). Consistently, in NPHS1-6- and NEPH-3(RNAi) planarians, we could not observe ultrastructural evidence of flame cell detachment at the time that loss of ultrafiltration was observed (not shown). Evidence from a rat model of nephrotic syndrome indicates that the upregulation of transcytotic transport processes across the effaced podocyte envelope could maintain a basal level of non-size-selective fluid flow (Tojo et al., 2008; Kinugasa et al., 2011; Tojo and Kinugasa, 2012), yet the exact mechanisms remain to be determined in both humans and planarians. Regardless, the striking parallels between the NPHS1-6- and NEPH-3(RNAi) phenotypes in planarians and human nephrotic syndrome demonstrate that the functional homology between planarian flame cells and vertebrate podocytes extends to common pathologies.

\section{Cyst formation in planarian PTs}

Encouraged by these results, we expanded our search for conserved pathologies to the protonephridial tubules. The most common class of human inherited disorders affecting the nephron 

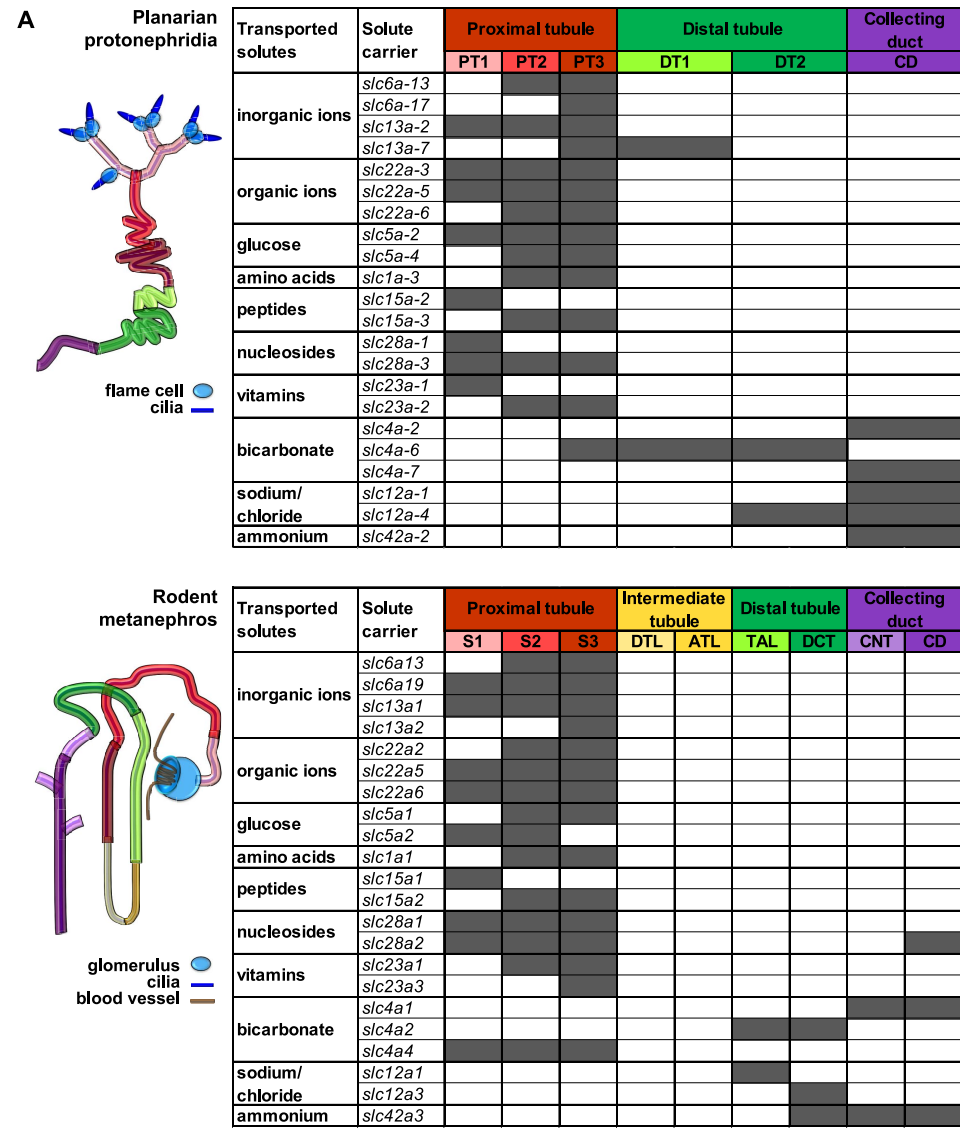

B
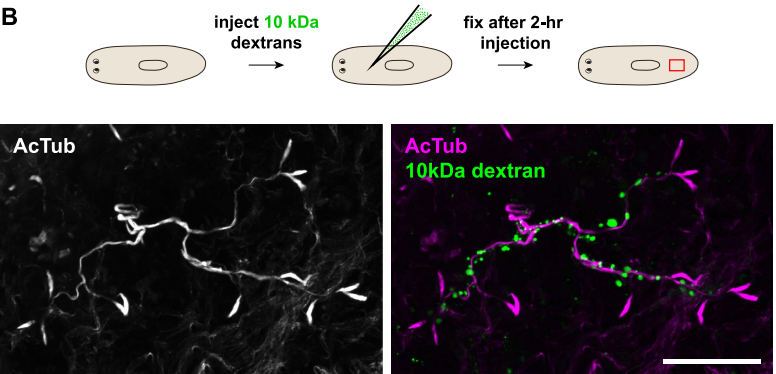

C

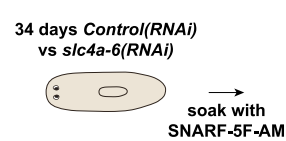

mage at both

Control(RNAi)

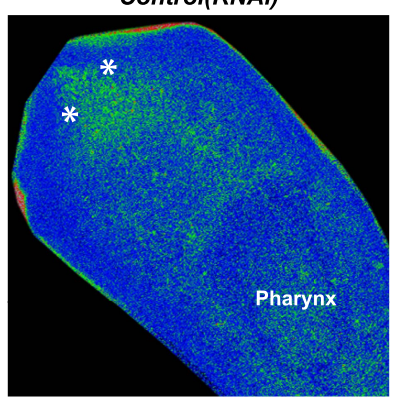

Acidic

Acidic
(low pH) $640 \mathrm{~nm}$ ( $\mathrm{pH}$ sensitive) \& $580 \mathrm{~nm}$ ( $\mathrm{pH}$ insensitive) wavelengths

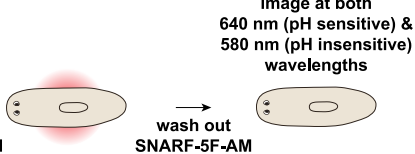

s/c4a-6(RNAi)

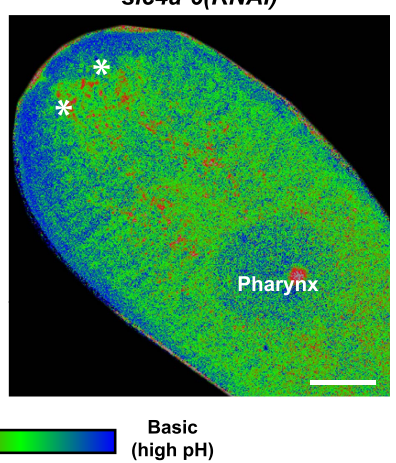

Figure 3. Extensive structural and functional homology between planarian protonephridia and vertebrate nephrons. (A) Tables summarize expression domains of selected slc genes in planarian protonephridia and rodent metanephros. Cartoons showing segmental organization of planarian protonephridia and rodent metanephros are on the left. Gray color in the tables indicates expression domain of slc in planarian protonephridia and rodent metanephros. Planarian slc sequence nomenclature (e.g., slc1a-3) doesn't reflect direct orthology to the mammalian counterparts. Abbreviations for segments of protonephridia are as follows: PT1, PT2, and PT3, segments of the proximal tubule (PT); DT1 and DT2, segments of the DT; CD, the collecting duct. Abbreviations for segments of the metanephros are as follows: S1, S2, and S3, segments of the PT; DTL, descending thin limb; ATL, ascending thin limb; TAL, thick ascending limb; DCT, distal convoluted tubules; CNT, connecting tubule; CD, collecting duct. (B) Fluorescent overlay of reabsorbed dextran with PT marker (AcTub). (C) $\mathrm{pH}_{\mathrm{i}}$ reporter assay using SNARF-5F-AM in Control(RNAi) and slc4a-6(RNAi).

DOI: 10.7554/eLife.07405.026

are the CKDs. We assembled a small library of putative planarian orthologues of human CKD genes (Supplementary file 4). This list included the nephrocystins, causative genes of nephronophthisis (NPHP), one of the most frequent genetic causes of chronic renal failure in children and young adults (Hildebrandt and Otto, 2000; Salomon et alo, 2009). The S. mediterranea genome harbors homologs to human NPHP1-9, except for NPHP2 and NPHP3 (Figure 5-figure supplement 1). RNAi-screening of the library revealed strong edema formation in Smed-NPHP5, Smed-NPHP6, and Smed-NPHP8 knockdown animals (Figure 4A), suggesting a protonephridial function for these genes. Consistently, we detected severe structural alterations of protonephridial tubules in NPHP(RNAi) animals, particularly of the proximal segment. RNAi animals presented striking clump-like accumulations of PT marker expressing cells (Figure 5A,B, Videos 4,5) instead of the fine terminal ramifications of PTs in controls. High-resolution imaging confirmed the presence of abnormally high numbers of densely packed PT cells (Figure 5-figure supplement 2). The protonephridial lumen was severely disorganized within such aggregates (Figure $5 \mathrm{C}$ ). Instead of strong and continuous luminal labeling throughout the coiled PT segments of controls, labeling was weak and fragmented. The weak single-line labeling outside of aggregates (Figure $5 \mathrm{C}$ ) and the much weaker cilia staining (AcTub) in NPHP(RNAi) animals (Figure 5A) suggested general lumen defects. EM images revealed frequent 
A

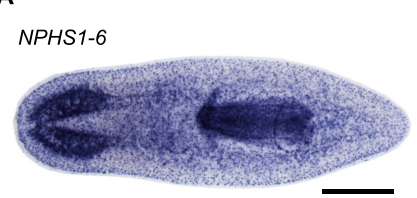

$N E P H-3$

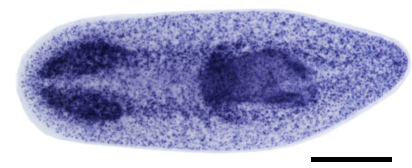

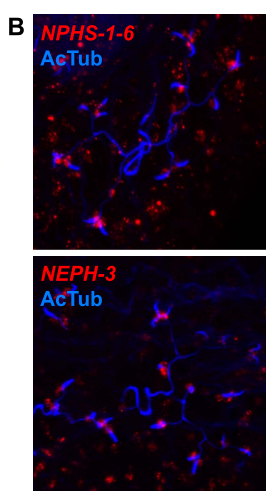
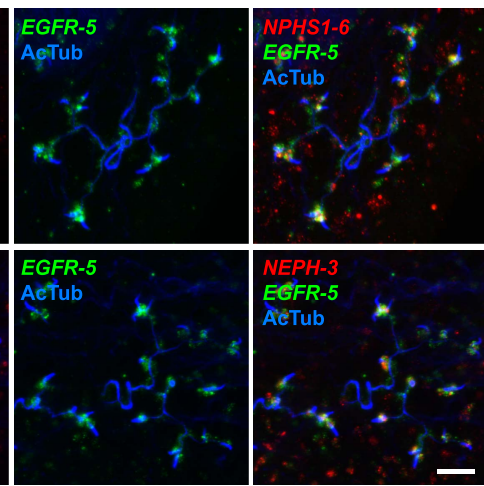

NPHS1-6(RNAi)
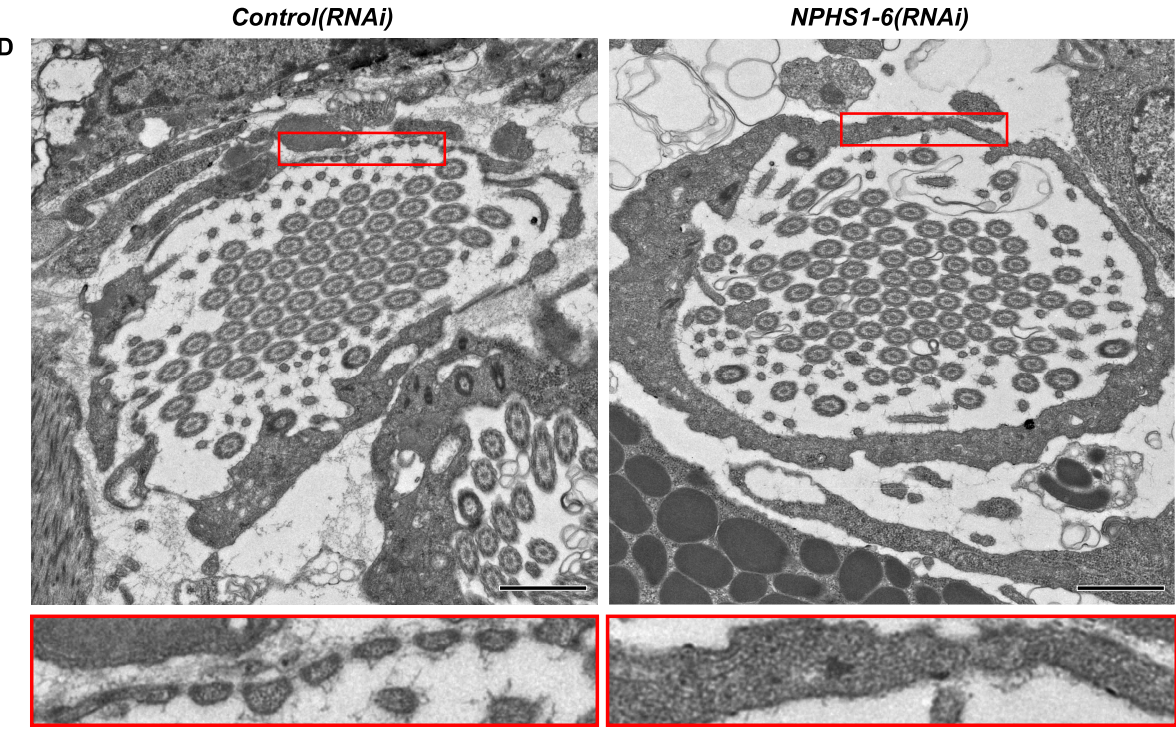

E
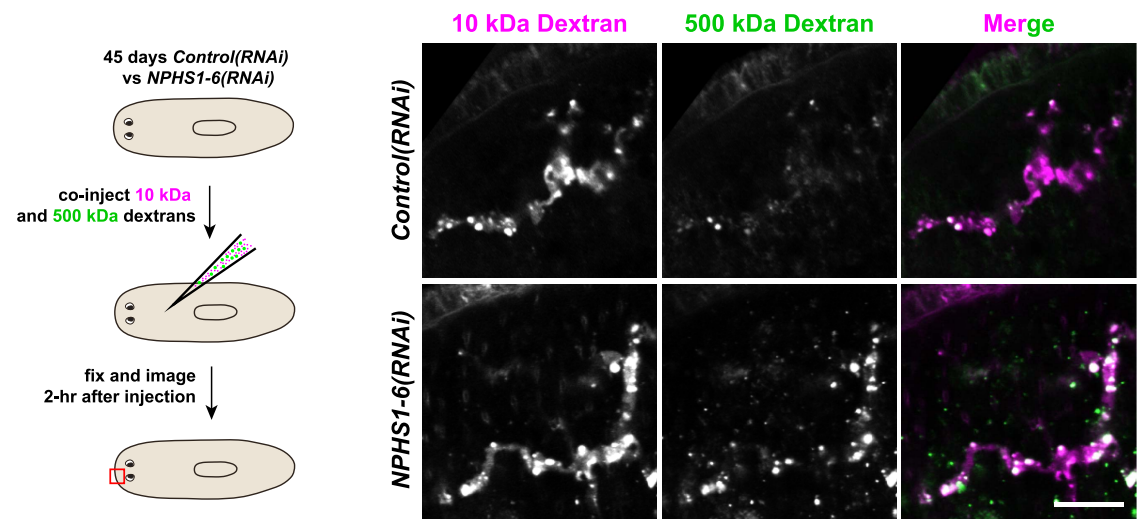
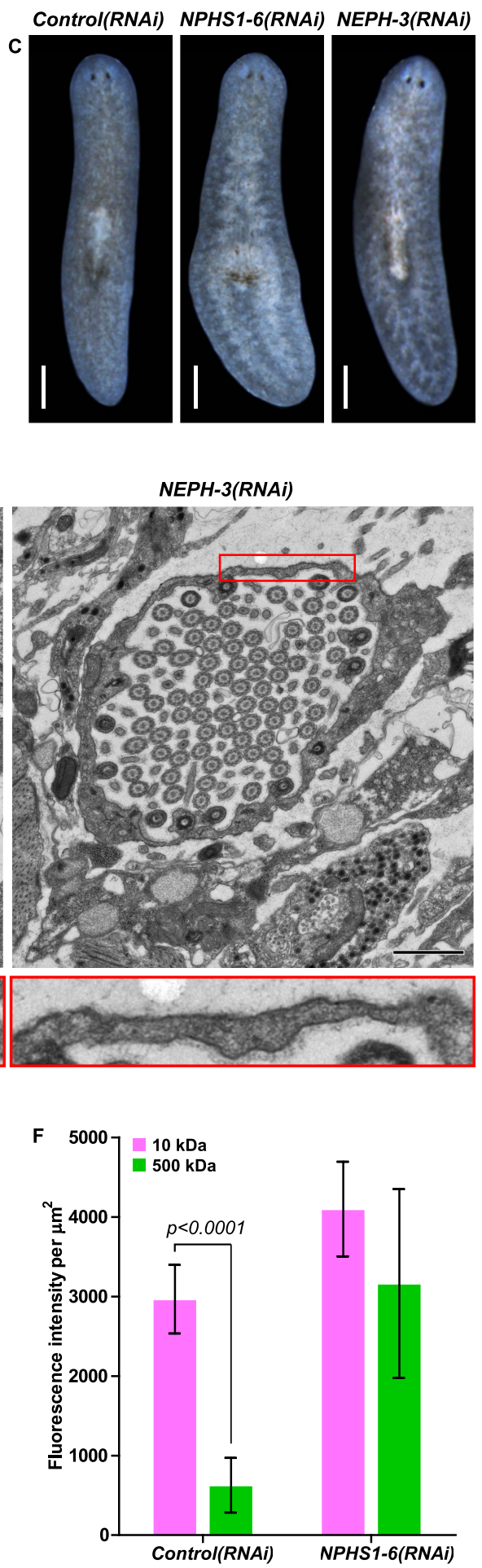

Figure 4. Vertebrate slit-diaphragm components are expressed in planarian flame cells and are required for the maintenance of their filtration diaphragm. (A) Whole-mount expression patterns of indicated marker genes by in situ hybridization (NBT/BCIP development). Scale bars: $500 \mu \mathrm{m}$. (B) Fluorescent overlay of indicated gene (red) with flame cell marker EGFR-5 and AcTub staining. Images are maximum projections of confocal Z-sections. Scale bars: $50 \mu \mathrm{m}$. (C) Live images show edema in intact NPHS1-6(RNAi) and NEPH-3(RNAi) animals. Scale bars: $500 \mu \mathrm{m}$. (D) TEM images show cross-section through a flame cell in intact Control(RNAi), NPHS1-6(RNAi) and NEPH-3(RNAi) animals. Inset shows a high magnification of the filtration diaphragm. Scale bar: Figure 4. continued on next page 
Figure 4. Continued

$1 \mu \mathrm{m}$. (E, F) Ultrafiltration assay assesses the ultrafiltration capacity in NPHS1-6(RNAi) animals. (E) Representative images show dextran uptake in the animals that co-injected with $10 \mathrm{kDa}$ and $500 \mathrm{kDa}$ fluorescently labeled dextran. Scale bar: $50 \mu \mathrm{m}$. (F) Quantification of small and large dextran uptake. DOI: 10.7554/eLife.07405.027

The following figure supplements are available for figure 4:

Figure supplement 1. Slit-diaphragm components in the planarian S. mediterranea.

DOI: 10.7554/eLife.07405.028

Figure supplement 2. NPHS1-6 is not required for flame cell viability during normal homeostasis, as well as regeneration.

DOI: 10.7554/eLife.07405.029

Figure supplement 3. NPHS1-6 is required for de novo formation of filtration diaphragm during regeneneration.

DOI: 10.7554/eLife.07405.030

basal body mislocalizations to non-luminal membrane domains and cell intrusions into the lumen, which both indicate a loss of normal tubular cell polarity (Figure 5-figure supplement 3). Altogether, the accumulation of morphologically abnormal tubule cells and concomitant loss of luminal connectivity present striking morphological parallels to the NPHP loss-of-function phenotype in humans, suggesting that planarian protonephridia can develop cyst-like structures.

\section{Protonephridial cysts originate from direct proliferation of protonephridial progenitors}

Sustained cell proliferation in the renal tubules is a hallmark of cystic kidneys in humans and the severity of the phenotype correlates with the ectopic proliferation level (Wilson and Goilav, 2007). We used BrdU pulse labeling to determine whether cell proliferation was involved in the formation of the observed cyst-like structures (Figure 6A). In controls, we found occasional cells double positive for BrdU and the protonephridial progenitor marker Smed-POU2/3 (Scimone et al., 2011) in the vicinity of tubules (Figure 6A), consistent with the emerging view that all planarian cell types derive from the proliferation of specific progenitor classes within the neoblast population (Cowles et al., 2013; Adler et al., 2014; Scimone et al., 2014; van Wolfswinkel et al., 2014). In NPHP8(RNAi) animals, the number of BrdU/POU2/3 double-positive cells in the vicinity of cell accumulations was notably increased (Figure 6A), and in situ analyses further confirmed the progressive accumulation of protonephridial progenitors (Figure 6-figure supplement 1A-D). To probe the magnitude of

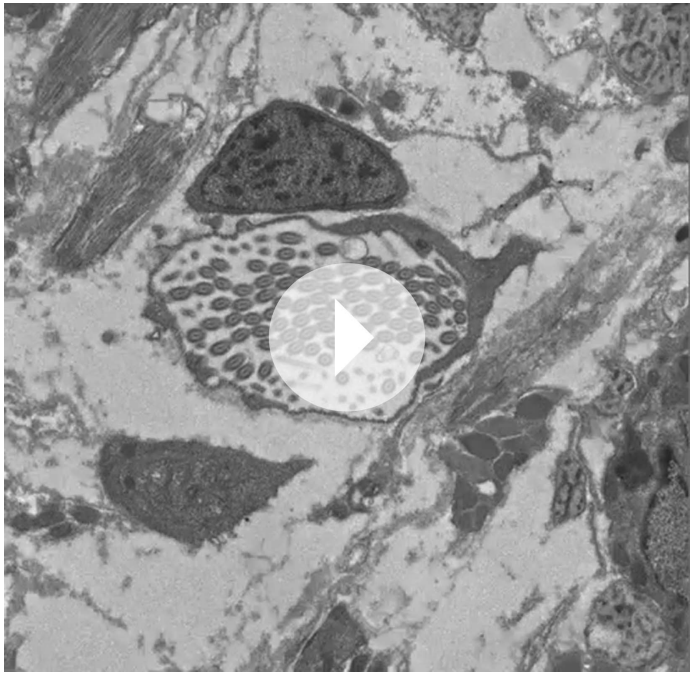

Video 2. Flame cell morphology in Control(RNAi) animal. Serial TEM images showing flame cell in Control (RNAi) animal.

DOI: 10.7554/eLife.07405.031

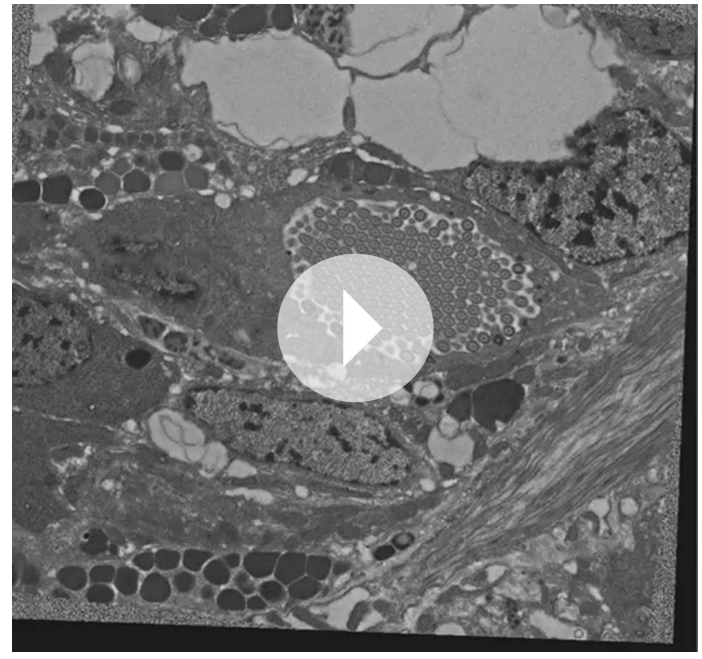

Video 3. Flame cell morphology in NPHS1-6(RNAi) animal. Serial TEM images showing flame cell in NPHS16(RNAi) animal.

DOI: 10.7554/eLife.07405.032 

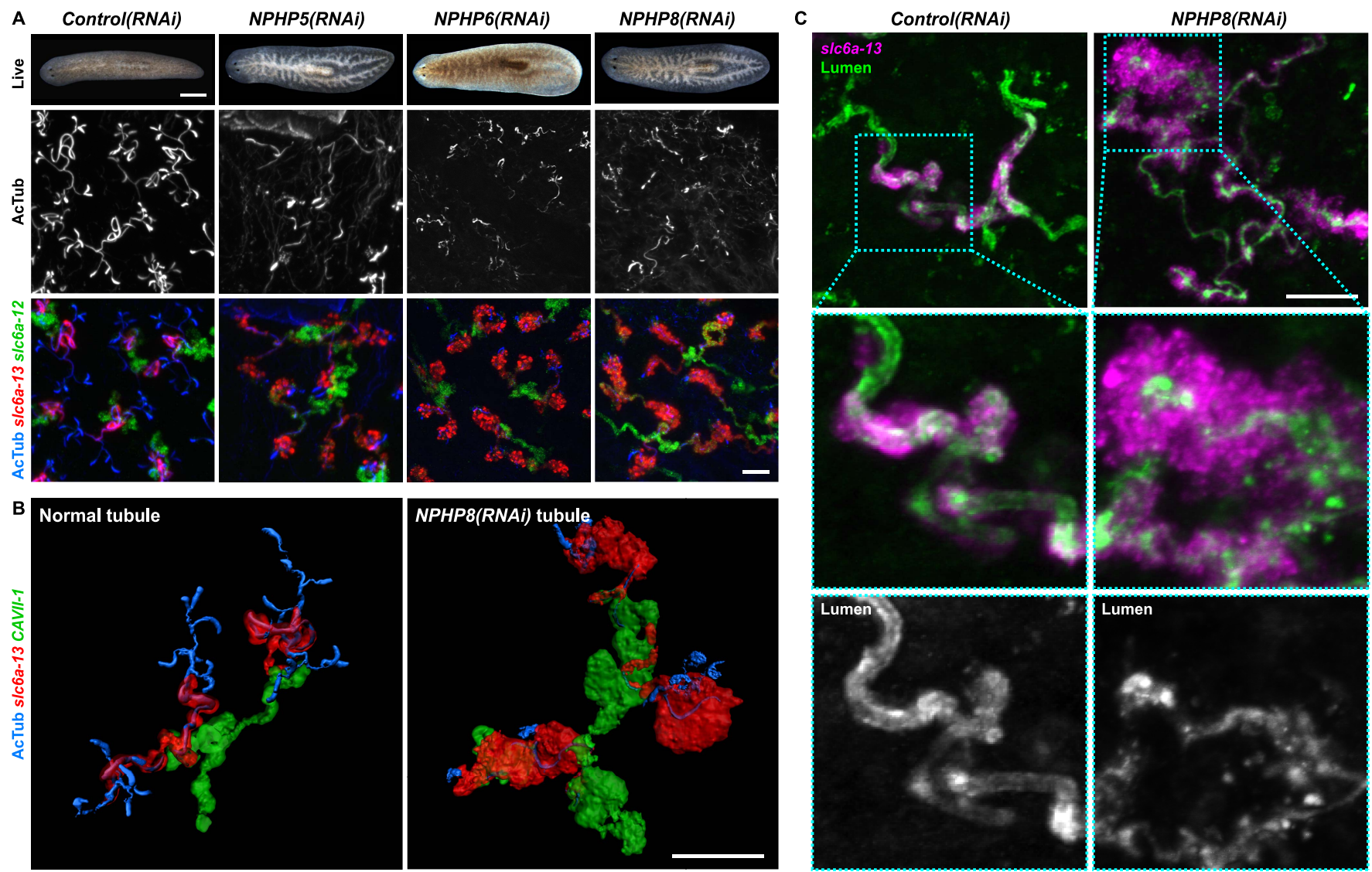

Figure 5. Down-regulation of nephrocystin members leads to the formation of cyst-like structure in protonephridia. (A) Protonephridial defects in NPHP5 (RNAi), NPHP6(RNAi) and NPHP8(RNAi) animals. Top panel: live images show edema in intact RNAi animals. Scale bars: $500 \mu$ m; middle panel: monochrome showing AcTub staining; bottom panel: fluorescent overlay of AcTub staining with PT2 and PT3 marker (slc6a-13) and DT marker (slc6a-12) Scale bars: $50 \mu \mathrm{m}$. (B) 3D rendering images showing normal tubule and cystic-like tubule in Control(RNAi) and NPHP8(RNAi) animals, respectively. 3D rendering was performed in IMARIS. Scale bars: $50 \mu \mathrm{m}$. (C) Fragmented lumen in enlarged protonephridial tubule. Fluorescent overlay of PT2 and PT3 marker slc6a-13 and lumen marker (a customized rabbit antiserum recognized unknown epitope) in intact Control(RNAi) and NPHP8(RNAi) animals. Scale bars: $50 \mu \mathrm{m}$. Images in $(\mathbf{A})$ and $(\mathbf{C})$ are maximum projections of confocal Z-sections.

DOI: $10.7554 /$ LLife. 07405.033

The following figure supplements are available for figure 5:

Figure supplement 1. Nephrocystins in the planarian S. mediterranea.

DOI: 10.7554/eLife.07405.034

Figure supplement 2. Abnormal tubular enlargement in NPHP8(RNAi) animals.

DOI: 10.7554/eLife.07405.035

Figure supplement 3. Ultrastructure of the PT in NPHP(RNAi) animals.

DOI: 10.7554/eLife.07405.036

the overproliferation effect, we carried out whole-mount staining with the G2/M-phase marker phospho-Histone $\mathrm{H} 3(\mathrm{H} 3 \mathrm{P})$ and found a global increase in cell proliferation in NPHP(RNAi) animals (Figure 6B). To ask whether these effects were specific to protonephridial progenitors or globally affected all progenitor classes, we quantified the relative fraction of proliferation in protonephridial$\left(\right.$ POU2 $/ 3^{+} /$smedwi- $\left.1^{+} / \mathrm{H} \mathrm{P}^{+}\right)$, neuronal- $\left(\right.$pax6 $\mathrm{A}^{+} /$smedwi- $\left.1^{+} / \mathrm{H} \mathrm{P}^{+}\right)$(Wenemoser et al., 2012; Scimone et alo, 2014) and intestinal $\left(\mathrm{HNF}^{+} / \mathrm{smedwi}^{-} 1^{+} / \mathrm{H}^{3} \mathrm{P}^{+}\right)$(Wagner et alı, 2011; Scimone et al., 2014) progenitor classes (Figure 6-figure supplement 1C,D, Figure 6-figure supplement 2). Whereas the fraction of proliferating protonephridial progenitors was increased in both NPHP5(RNAi) and NPHP8(RNAi) animals, we found no change in the fraction of proliferating neuronal progenitors and even a slight decrease in intestinal progenitor proliferation (Figure 6C-E). The observation that all 


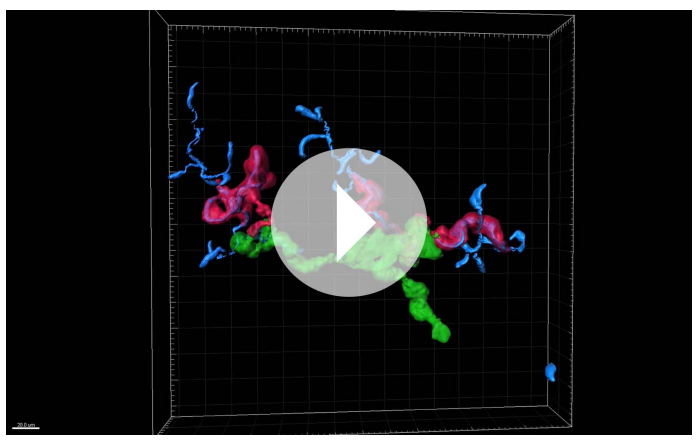

Video 4. 3D rendering of normal protonephridial tubule in Control(RNAi) animal. DOI: 10.7554/eLife.07405.037

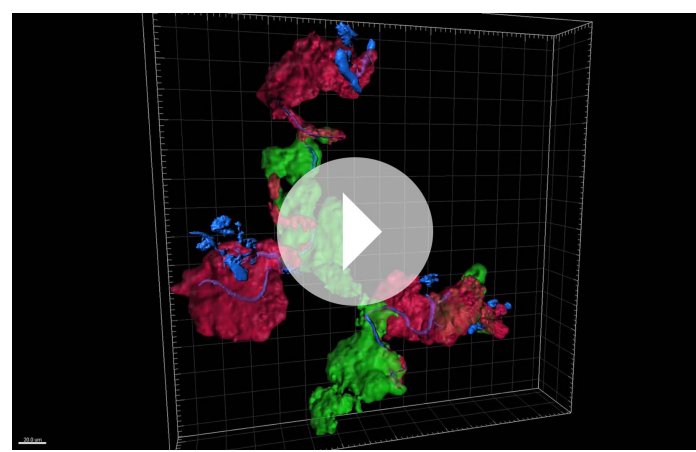

Video 5. 3D rendering of cystic-like protonephridial tubule in NPHP8(RNAi) animal.

DOI: 10.7554 /eLife.07405.038

cases of ectopic BrdU-incorporation in the normally division-devoid area anterior to the photoreceptors were limited to $\mathrm{POU} 2 / 3^{+}$protonephridial progenitors (Figure 6-figure supplement 1E) further supports the protonephridial specificity of the overproliferation response. Altogether, these results demonstrate that loss of function of planarian NPHP genes selectively increased the proliferation of protonephridial progenitors.

To test whether the level of proliferation determined the severity of the phenotype as observed in humans, we made use of the facile manipulation of global cell proliferation levels in the planarian system (Figure 6F, Figure 6-figure supplement 3A). Lethally or sub-lethally irradiated animals were used to examine the effects of abolished or reduced proliferation, respectively (Wagner et al., 2012), while animals on an increased feeding regiment provided an opportunity to examine the effects of above-baseline proliferation (Kang and Sanchez Alvarado, 2009). We found that edema development in NPHP8(RNAi) animals was faster and more severe under the increased proliferation condition, yet significantly diminished or even abolished under reduced or no proliferation, respectively (Figure 6G-J, left). The quantification of the confocally projected area of protonephridial marker expression domains (slc6a-13 and CAVII-1) as a direct cell accumulation metric (Figure 6G-J, right; Figure 6-figure supplement 3B) also showed equal dependency on proliferation rates, thus indicating that the development of planarian NPHP phenotypes is tightly associated with cell proliferation.

In light of the striking morphological and ontological parallels between protonephridial and human NPHP loss-of-function phenotypes, we now refer to the observed structural alterations in planarian protonephridia as cysts.

\section{Cilia-driven fluid flow is required for tubular cell homeostasis in planarian protonephridia}

Cilia as flow sensors play a critical role in the ontogeny of human CKDs (Hildebrandt and Otto, 2005; Hildebrandt and Zhou, 2007; Kotsis et al., 2013). NPHP(RNAi) planarians display severe defects in cilia-driven gliding motility (Figure 7A,B), prompting us to investigate a possible involvement of cilia in the ontogeny of planarian protonephridial defects. Direct visualization of axonemes in NPHP(RNAi) animals indeed confirmed structural cilia defects, which appeared shorter (NPHP5(RNAi)) or much reduced in density (NPHP6/8(RNAi)) (Figure 7C). EM images revealed abnormal localization of centrioles as well as axonemal abnormalities in ciliated cells under NPHP5/6/8(RNAi) (Figure 5-figure supplement 3). Together with the broad resemblance between NPHP5/6/8 expression patterns and typical cilia genes (Rink et al., 2009; Glazer et al., 2010) (Figure 5-figure supplement 1), these data conclusively demonstrate that knockdown of planarian NPHP-genes causes not only protonephridial cyst formation, but also structural defects in cilia.

Therefore, we decided to systematically test possible mechanistic roles of cilia in planarian cyst ontogeny. If cilia were generally required for maintaining the structure/function of protonephridia, then all disruptions of cilia structure should cause cystic phenotypes. We therefore knocked down Smed-IFT88, a component of the intraflagellar transport machinery. As previously shown 

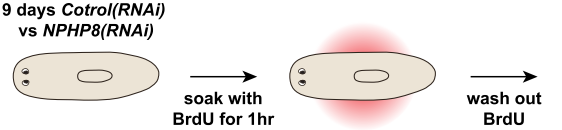

chase for $2 \mathrm{hr}$ BdU for $1 \mathrm{hr}$
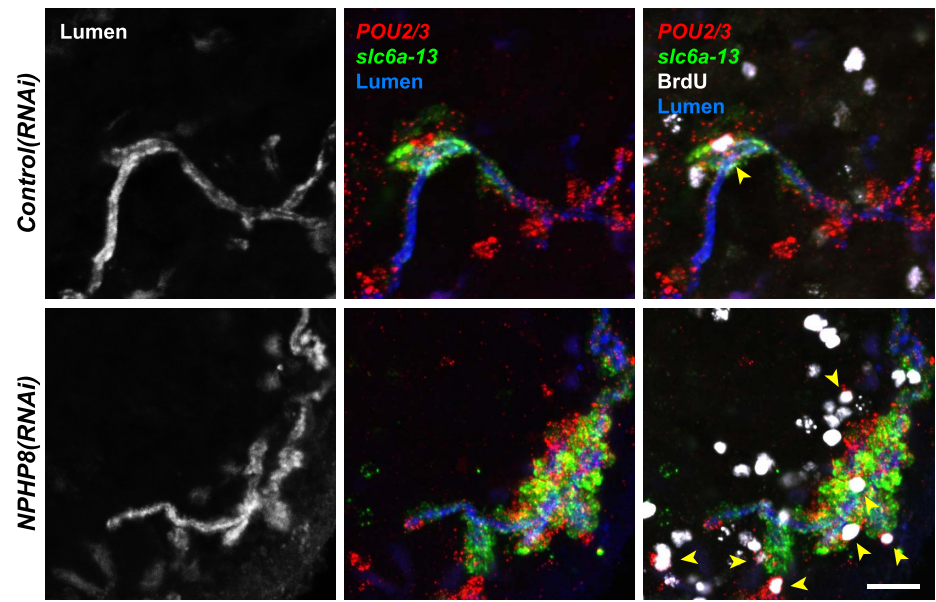

B
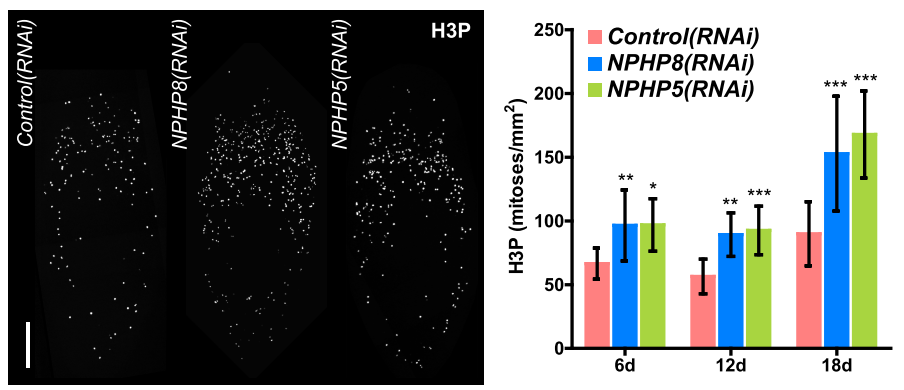

C

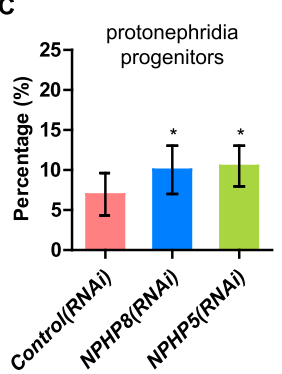

D

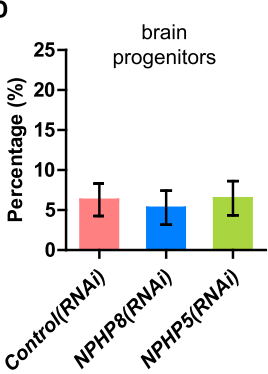

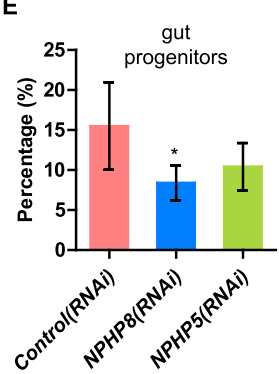

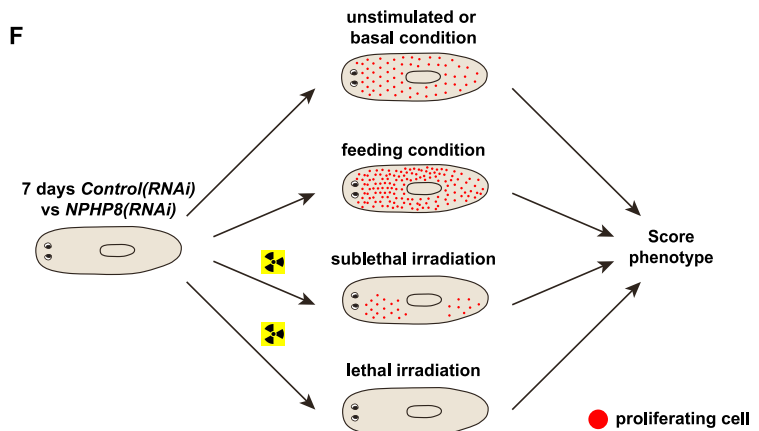

G basal
condition
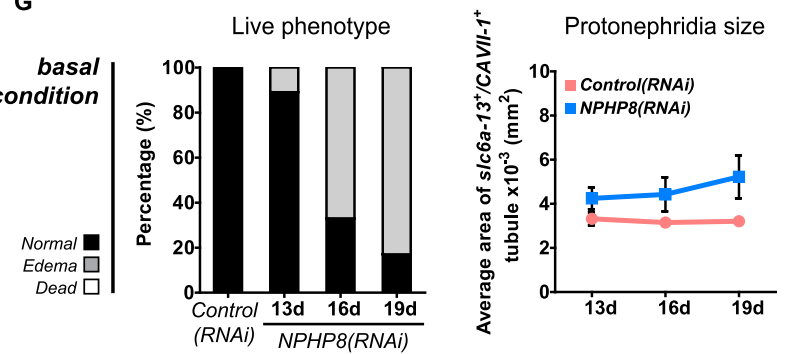

H
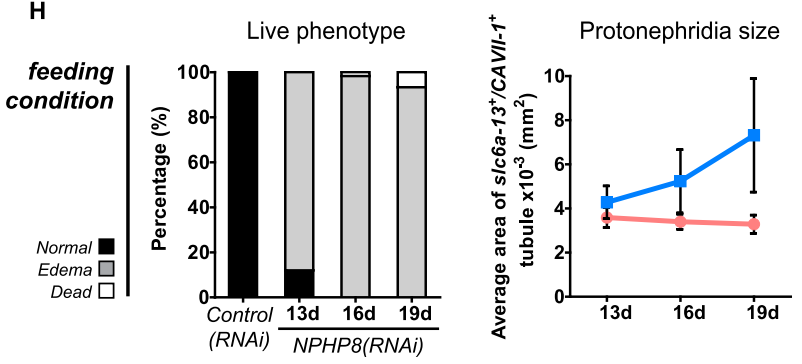$$
\text { I }
$$
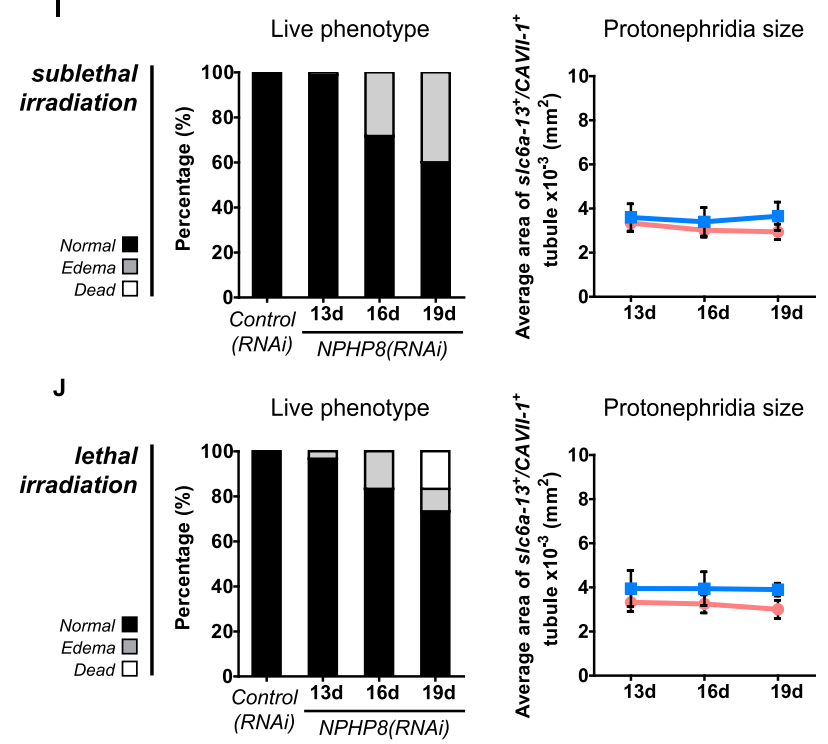

Figure 6. Cystogenesis in planarian protonephridia results from direct proliferation of protonephridia progenitors and requires the presence of stem cells. (A) BrdU pulse-chase experiment shows the presence of diving protonephridial progenitors in the proximity of protonephridial tubule in Control(RNAi) and NPHP8(RNAi) animals. Yellow arrowhead indicates POU2/3+/BrdU cell. Scale bars: $25 \mu \mathrm{m}$. (B) Increased global proliferation in NPHP5(RNAi) and NPHP8(RNAi) animals is displayed by immunostaining of mitotic marker phospho-Histone H3 (H3P). Scale bars: $500 \mu \mathrm{m}$. ${ }^{*} p<0.05$; ${ }^{* \star} p<0.01$; ${ }^{* * *} p<0.001$ vs control. The time points in the bar graph indicate the number of day after the last dsRNA introduction. (C-E) Quantification of (C) dividing protonephridial progenitors $\left(\mathrm{POU} 2 / 3^{+} / \mathrm{H} 3 \mathrm{P}^{+}\right)$, (D) diving neuronal progenitors $\left(\right.$pax $\left.6 \mathrm{~A}^{+} / \mathrm{H}^{3} \mathrm{P}^{+}\right)$and $(\mathbf{E})$ diving gut progenitors $\left(\mathrm{HNF} 4^{+} / \mathrm{H} 3 \mathrm{P}^{+}\right)$among diving Figure 6. continued on next page 
Figure 6. Continued

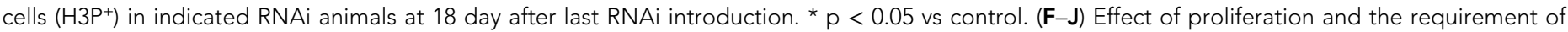
neoblasts on cyst formation in planarian protonephridia. (F) Schematics demonstrates experimental strategy for panel H-J. 7 day post RNAi feeding animals were either fed with liver to induce cell proliferation or subjected to sublethal or lethal doses of irradiation to reduce or eliminate neoblasts. Scoring live phenotype as well as measuring the average size of each protonephridial unit was used to evaluate the severity of cystic phenotype. Temporal succession of indicated phenotypes (left) and quantification of average area of each slc6a13+CAVII- $1^{+}$tubule (right) in Control(RNAi) and NPHP8(RNAi) animals under (G) basal condition (only RNAi feeding), (H) basal condition plus extra feeding with liver, (I) basal condition plus sub-lethal irradiation to reduce the number of neoblasts, and (J) basal condition plus lethal irradiation to completely eliminate neoblasts. The time points in the bar graphs (G-J) indicate the number of the day after the first dsRNA introduction.

DOI: 10.7554/eLife.07405.039

The following figure supplements are available for figure 6:

Figure supplement 1. Increase of protonephridial progenitors during cystogenesis in planarian protonephridia. DOI: 10.7554/eLife.07405.040

Figure supplement 2. Gut and brain progenitors in NPHP8(RNAi) animals. DOI: 10.7554 /eLife.07405.041

Figure supplement 3. The severity of cystic phenotype in protonephridia depends on proliferation rate and requires the presence of stem cells. DOI: 10.7554/eLife.07405.042

(Rink et al., 2009), IFT88(RNAi) animals lost their cilia-dependent gliding ability (Figure 7-figure supplement 1A), developed massive tissue edema and had severely shortened cilia (Figure $7 E, E^{\prime}$ ). Interestingly, IFT88(RNAi) animals also developed cystic protonephridia (Figure 7E') and cystogenesis in IFT88(RNAi) animals was also associated with increased proliferation (Figure 7-figure supplement 2) and the abnormal accumulation of protonephridial progenitors (Figure 7E'"). These results therefore demonstrate that disruption of cilia is sufficient for cyst development in planarians.

In contrast to adult mammalian kidneys that contain only immotile sensory cilia (Webber and Lee, 1975), the excretory systems of planarians and many other lower vertebrates possess motile cilia (Figure 7-figure supplement 1B; [McKanna, 1968a, 1968b; Ishii, 1980a, 1980b; Lacy et al., 1989; Kramer-Zucker et al., 2005; Rink, 2013]) that collectively drive fluid flow into and through the tubules (White, 1929; Pontin, 1964; Warner, 1969; Kramer-Zucker et al., 2005). Hence cilia-dependent cyst formation might reflect either a requirement of cilia as flow generators and/or as flow sensors. We first sought to disrupt ciliary beating without gross changes in cilia length or structure. We therefore targeted two planarian homologues of Primary Ciliary Dyskinesia (PCD) disease genes, a rare ciliopathy causing general cilia immobility in humans (Badano et al., 2006) (Figure 7-figure supplement $1 B, C$ ). Disrupting the function of Smed-DNAH $\beta-1$ and Smed-LRRC50 by RNAi led to abnormal gliding ability (Figure 7-figure supplement 1A) due to loss of ciliary beating (Figure 7H-I; Videos 6-8), while cilia length and structure appeared unaffected (Figure $7 F^{\prime}-G^{\prime}$ ). Interestingly, DNAH $\beta-1$ - and LRRC5O(RNAi) animals also developed edema and formed protonephridial cysts (Figure $7 F, G, F^{\prime \prime}, G^{\prime \prime}, F^{\prime \prime \prime}, G^{\prime \prime \prime}$ ). These results indicate that reduced ciliary beating rate without change in cilia structure is sufficient to cause the cystic phenotype in planarian protonephridia. Together, these results suggest that cilia-driven fluid flow is crucial to orchestrate tubular cell homeostasis in planarian protonephridia.

\section{Discussion}

Our study has uncovered remarkable molecular and functional similarities between the basic functions of planarian protonephridia and those of the vertebrate nephrons. First, key constituents of the vertebrate podocyte slit diaphragm (NPHS1 and NEPH1) are not only expressed, but also required for planarian flame cell ultrafiltration function (Figure 4). Our data, combined with recent studies in flies (Weavers et al., 2009; Zhuang et al., 2009) demonstrate a deep evolutionary conservation of NPHS1 and NEPH1 function in ultrafiltration barrier maintenance in planarian flame cells, insect nephrocytes, and vertebrate podocytes. Second, the systematic gene expression mapping of slc families in the planarian protonephridial tubule revealed striking topological parallels to the vertebrate pronephros/ metanephros (Figure 3A). Our results demonstrate functional homologies between sub-segments of the vertebrate nephrons and planarian protonephridia. Third, the extensive structure/function homologies between planarian protonephridia and vertebrate nephrons encompass common pathologies. We found that many human kidney disease genes cause similar pathologies in planarian 

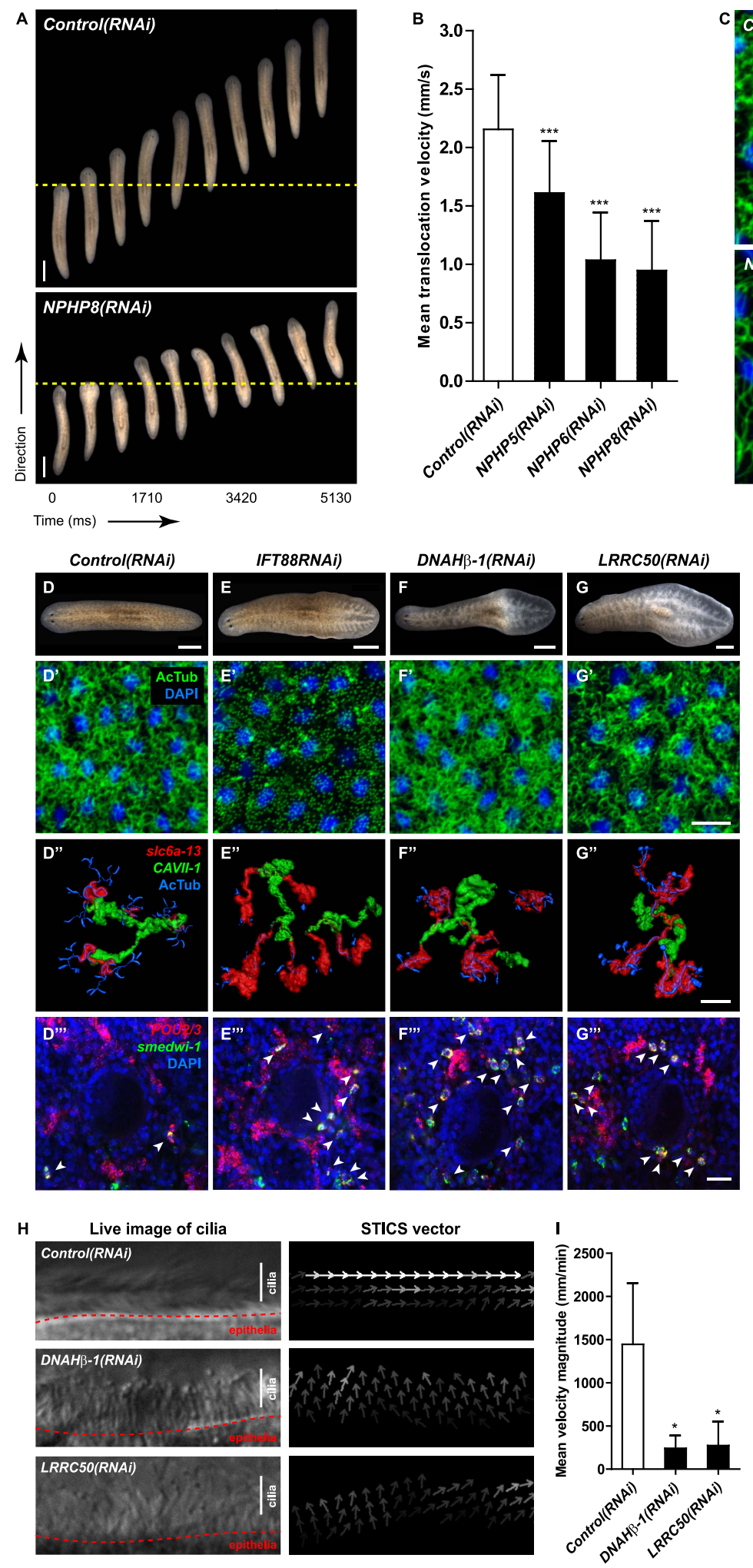
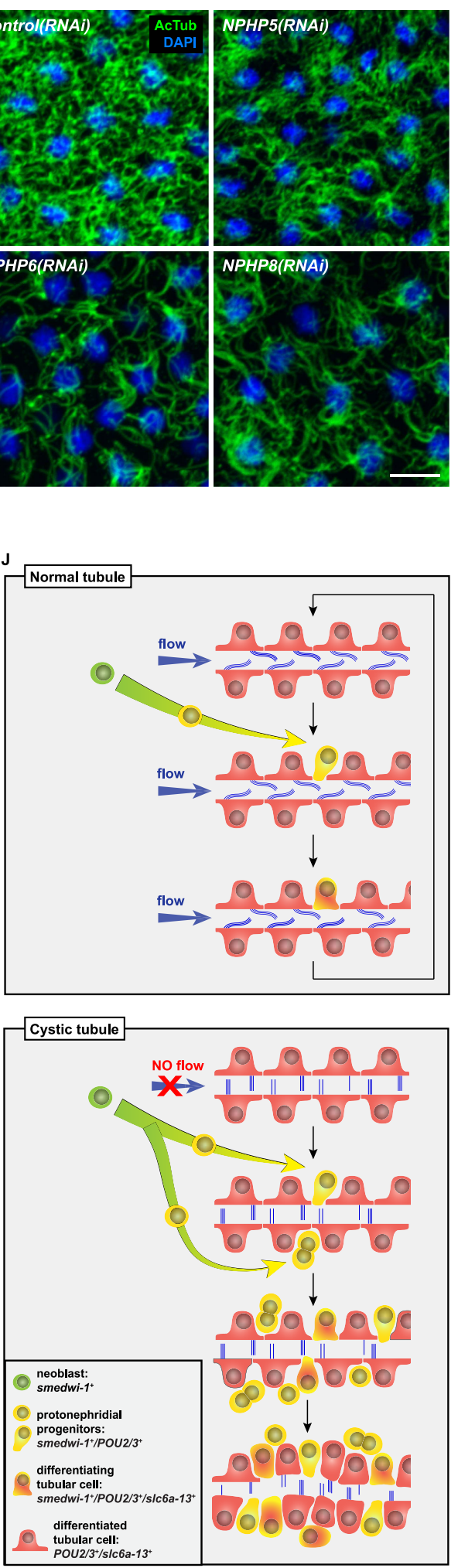

Figure 7. Cystic phenotype in protonephridia is cilia-and fluid flow-dependent. (A) Series of live images show gliding mobility in Control(RNAi) and NPHP8(RNAi) animals. Yellow dot line provides a spatial reference to illustrate progress of animal. Scale bar: $1 \mathrm{~mm}$. (B) Quantification of translocation speed in indicated RNAi animals. Error bar, SD; ${ }^{\star \star \star} p<0.001$ vs control. (C) Fluorescent overlay of ventral cilia (AcTub) with nucleus marker (DAPI) in Figure 7. continued on next page 
Figure 7. Continued

indicated RNAi animals. Scale bar: $10 \mu \mathrm{m}$. (D-G) Live images show bloating phenotype in IFT88(RNAi), DNAH $\beta$-1(RNAi), and LRRC50(RNAi) animals. Scale bar: $500 \mu \mathrm{m}$. (D'-G') Fluorescent overlay of ventral cilia (AcTub) with nucleus marker (DAPI) in IFT88(RNAi), DNAH $\beta$-1(RNAi), and LRRC50(RNAi) animals. Scale bar: $10 \mu \mathrm{m}$. ( $\left.\mathbf{D}^{\prime \prime}-\mathbf{G}^{\prime \prime}\right)$ 3D rendering showing fluorescent overlay of AcTub staining with PT2 and PT3 marker (slcba-13) and DT marker (CAVII-1) in

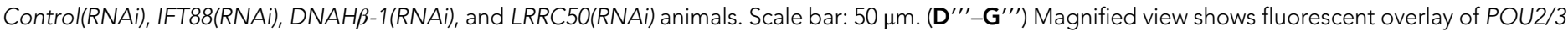
with pan stem cell marker (smedwi-1) in the region surrounding photoreceptor. White arrowhead shows $P O U 2 / 3^{+} / \mathrm{smedwi}^{+} \mathbf{1}^{+}$cell. Scale bar: $25 \mu \mathrm{m}$. $(\mathbf{H}-\mathbf{I})$ Abnormal cilia beating in DNAH $\beta-1(R N A i)$, and $L R R C 50(R N A i)$ animals. $(\mathbf{H})$ Left panel: live images show cilia beating along the lateral body edge of the planarian head region; Right panel: vector map generated by Spatiotemporal image correlation spectroscopy (STICS) analysis shows velocity magnitude and beating pattern of cilia. The brightness of the vector represents the velocity magnitude of the cilia: brighter vector, stronger ciliary beating or vice versa. (I) Quantification of ciliary velocity magnitude in indicated RNAi animals. * $p<0.05$ vs control. (J) Cartoon represents working model of cyst formation in the planarian protonephridia. In normal tubule, protonephridial tubular cell turnover is maintained by integration of protonephridial progenitors, originated from the neoblasts, into the tubule. During this process, cilia-driven fluid flow is required for the maintenance of tubular geometry. Obstruction of fluid flow by disrupting cilia function leads to protonephridial cystogenesis that characterized by abnormal proliferation of protonephridial progenitors, tubular enlargement and disorganization.

DOI: 10.7554/eLife.07405.043

The following figure supplements are available for figure 7:

Figure supplement 1. Primary Ciliary Dyskinesia (PCD) genes in the planarian S. mediterranea. DOI: 10.7554/eLife.07405.044

Figure supplement 2. Cystogenesis in planarian protonephridia under IFT88(RNAi) is correlated with increased proliferation. DOI: 10.7554/eLife.07405.045

protonephridia, most notably cyst formation upon NPHP knockdown. Altogether, our comprehensive molecular, structural, and functional characterization of the planarian protonephridia strongly supports a common evolutionary origin for the excretory systems of bilateral metazoans.

\section{Planarian protonephridia represent a novel invertebrate model for human kidney diseases}

An important consequence of these findings is that planarian protonephridia provide an invertebrate model for human kidney diseases. Both human nephrons and planarian protonephridia rely on pressure-driven ultrafiltration with subsequent filtrate modification during its passage through the nephridial tubules. This common design principle is significant for two reasons: first, many human kidney pathologies involve filtrate flow (see below); and second, the excretory systems of existing invertebrate model systems do not recapitulate this critical aspect. In fruitflies and other insects, ultrafiltration and filtrate modifications are carried out in separate cell types and organs (ultrafiltration: nephrocytes; filtrate modification: Malpighian tubules) (Dow and Romero, 2010). C. elegans has a highly derived excretory system consisting of just a single cell (Buechner, 2002). Both are therefore unsuitable for modeling flow-related kidney diseases, including polycystic kidney disease (PKD). PKD is one of the most common, life-threatening genetic diseases that affects millions worldwide

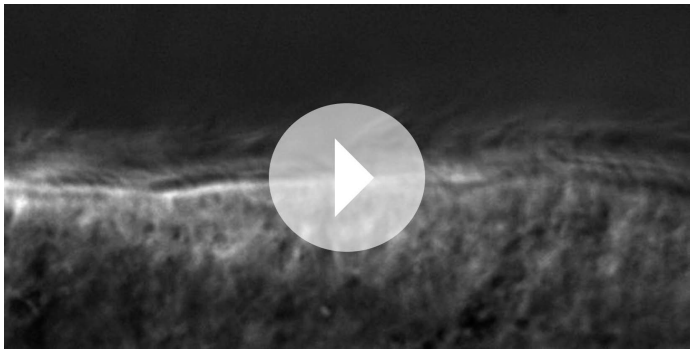

Video 6. Cilia beating in Control(RNAi) animal. Serial images show beating of the cilia along the lateral body edge of the planarian head region in Control(RNAi) animal.

DOI: 10.7554/eLife.07405.046

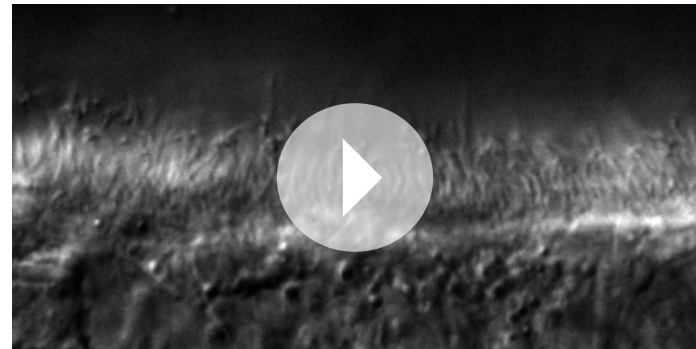

Video 7. Cilia beating in DNAH $\beta-1$ (RNAi) animal. Serial images show beating of the cilia along the lateral body edge of the planarian head region in DNAH $\beta-1$ (RNAi) animal.

DOI: 10.7554/eLife.07405.047 


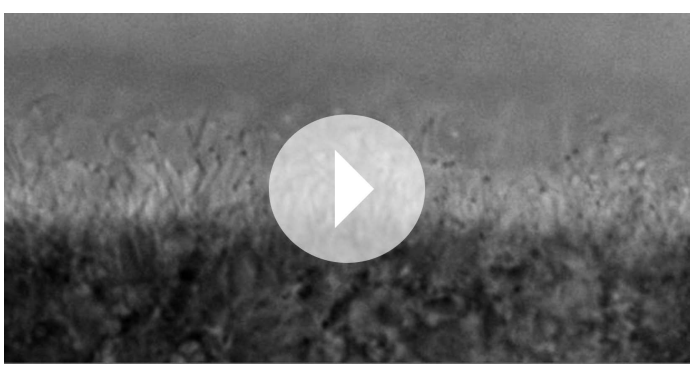

Video 8. Cilia beating in LRRC50(RNAi) animal. Serial images show beating of the cilia along the lateral body edge of the planarian head region in LRRC50(RNAi) animal.

DOI: 10.7554/eLife.07405.048 phenotypically very different. In vertebrates, individual nephron units combine within the kidney as a single organ, whereas in planarians, protonephridial units are pervasively present throughout the body (Rink et al., 2011). Further, in vertebrates, it is blood pressure and, ultimately, the heart that drives primary filtrate across the glomerular basement membrane and into the nephron. Planarians lack a circulatory system and therefore cannot solely rely on pressure-driven flow generation. The dense and vigorously beating cilia bundles of flame cells, and the multiciliated lining of the PT suggest instead that motile cilia are responsible for driving protonephridial ultrafiltration and flow. In fact, previous studies of protonephridia in other invertebrates strongly support this conclusion, including the direct observation of fluid flow cessation upon pharmacological inhibition of ciliary beating in the rotifer Asplanchna (Pontin, 1964; Warner, 1969).

The nephrons of the adult human kidney also bear cilia. However, in contrast to the multiciliated and flow generating cilia of the planarian PT, the cells of the adult mammalian nephron bear a single, immotile primary cilium protruding into the lumen (Webber and Lee, 1975). Despite these structural and functional differences, we find that cilia are similarly crucial for the maintenance of organ homeostasis in both systems. In humans, loss of function of many genes involved in cilia biogenesis/ function (Eley et al., 2005; Hildebrandt and Otto, 2005; Winyard and Jenkins, 2011; Kotsis et al., 2013) leads to overproliferation and cyst formation, including for example the NPHP proteins, that anchor the basal body to the cell membrane and are required for primary cilia formation (Betleja and Cole, 2010; Craige et al., 2010; Omran, 2010; Williams et al., 2011). The importance of cilia is thought to be due to their function as flow sensors (Winyard and Jenkins, 2011; Kotsis et al., 2013). Flowinduced bending is hypothesized to cause calcium influx via stretch sensitive polycystin channels, which subsequently inhibits cell proliferation via still unknown mechanisms (Praetorius and Spring, 2001, 2003; Nauli et al., 2003; Praetorius et al., 2004). Unexpectedly, in spite of the very different structure and function of planarian protonephridial cilia, we found that they are similarly critical in maintaining form and function of the organ system. First, knockdown of the planarian homologues of NPHP proteins lead to overproliferation of protonephridial progenitors. Second, the ablation of cilia by IFT88(RNAi) or the inhibition of ciliary beating by interfering with axonemal dyneins leads to protonephridial progenitor overproliferation. Moreover, in both cases, accumulating protonephridial progenitors form dense aggregates with disorganized lumens that quickly compromise the osmoregulatory functions of the organs, leading to edema formation. Hence the disruption of planarian cilia leads to phenotypically very similar alterations as PKD in vertebrates. We therefore conclude that cilia-mediated flow sensing constitutes an ancient mechanism for maintaining excretory organ homeostasis.

\section{Cilia play a dual role as flow generator and flow sensor in the planarian protonephridia}

Planarians have lost central components of centrosome duplication, which should therefore preclude their ability to form primary cilia (Azimzadeh et al., 2012). Since planarians only appear to harbor motile cilia, the corollary of this argument would be that the cilia of the protonephridial tubule have a dual role as flow generators and as flow sensors. Our data cannot conclusively address this point, because the 
currently available experimental paradigms do not allow the requisite uncoupling between cilia and flow. NPHP proteins are generally thought to only be essential for immotile sensory cilia (Eley et al., 2005; Badano et al., 2006; Ferkol and Leigh, 2012) based on their involvement in anchoring basal body to the cell membrane (Betleja and Cole, 2010; Craige et al., 2010; Omran, 2010; Williams et al., 2011). Loss of NPHP 'sensory' machinery in the multiciliated tubule cells leads to cyst formation in planarians, indicating the putative flow-sensing role of protonephridial cilia. However, bronchiectasis, a classic phenotypic feature of PCD, has been found in many cases of NPHP (Bagga et al., 1989; Bergmann et al., 2008; Moalem et al., 2013; Wolf, 2015) as well as autosomal dominant PKDs (Driscoll et al., 2008; Moua et al., 2014), indicating impaired motor cilia function. Conversely, phenotypic features of defective sensory cilia, including retinitis pigmentosa and cystic kidneys, have been reported in PCD patients (Kartagener and Horlacher, 1935; Saeki et al., 1984; Moore et al., 2006). These observations suggest an under-appreciated overlap between NPHP gene functions in motile cilia with that of PCD genes in immotile cilia, which makes it difficult to segregate flow generating and flow sensing roles of protonephridial cilia. However, recent work in vertebrate systems indicates that the transduction of sensory cues from the environment is a universal characteristic of all cilia, including motile cilia (Teilmann and Christensen, 2005; Shah et al., 2009), suggesting the likely existence of flow sensing role of motile cilia in planarian protonephridia (Schwartz et al., 1997; Teilmann and Christensen, 2005; Shah et al., 2009; Quarmby and Leroux, 2010; Takeda and Narita, 2012).

In humans, polycystin-1 and polycystin-2 are key components of cilia-mediated flow sensing (Praetorius and Spring, 2001, 2003; Nauli et al., 2003; Praetorius et al., 2004). As stretch-activated calcium channels, these proteins are thought to transduce the mechanical bending of the cilium into a chemical signal. Planarians have homologues of both polycystins and their knockdown leads to defects in ciliated dorsal mechanosensory neurons, but interestingly, not in protonephridia (Vu HTK and Rink JC, unpublished). Hence flow sensing in planarian protonephridia likely utilizes different mechanisms. The future elucidation of the underlying mechanisms may uncover general mechanistic links between flow sensing and flow generating in motile cilia.

\section{Cilia-driven fluid flow points to a shared ancestry of vertebrate and invertebrate excretory systems}

Given the extensive evolutionary homology between excretory systems, how can the exclusive reliance on motile cilia driven flow generation in invertebrates be reconciled with their absence in adult vertebrate kidneys? The loss of motile cilia in vertebrate kidneys has been observed in coincidence with the increase in blood pressure in birds and mammals (Marshall, 1934). This raises the possibility that the evolution of an extensively developed circulatory system in mammals rendered the flow-generating role of motile cilia redundant, and subsequently led to their loss from the adult kidney. The evidence for this hypothesis can be found in the embryology of the vertebrate kidney, which, as Ernst Haeckel argued, may indeed hint at phylogeny (Haeckel, 1866). Many vertebrates display multiciliated flow generation during early developmental stages (White, 1929; Lacy et al., 1989; Kramer-Zucker et al., 2005). For instance, the pronephric tubules of zebrafish contain multiciliated epithelial cells, and interference with cilia obstructs flow (Kramer-Zucker et al., 2005). In humans, motile cilia may even play a role at early kidney development, since multiciliated tubular cells have been observed at fetal stages (Zimmermann, 1971; Katz and Morgan, 1984). Furthermore, a number of human pathologies such as crescentic and membranoproliferative glomerulonephritis (Katz and Morgan, 1984; Hassan and Subramanyan, 1995), as well as focal segmental glomerulosclerosis (Katz and Morgan, 1984) are associated with the appearance of multiciliated tubular cells. This suggests that the gene regulatory programs for the development of multiciliated cells remain intact and accessible even in vertebrates. Altogether, these observations suggest that cilia-driven pressure generation may be the ancestral state for excretory systems, and that the immotile primary cilia of the adult vertebrate kidney represents an evolutionary vestige of the ciliadriven flow filtration observed in more basal excretory organs.

\section{Structural/functional abnormalities of cilia lead to cyst formation in excretory organs of both planarians and vertebrates}

Even though the exact flow sensing mechanisms remain to be identified, our data show that in planarians, these signals also affect cell proliferation. We observed a global increase of mitoses due to 
the specific overproliferation of protonephridial progenitors whenever cilia or fluid flow were affected (Figure 6B-E). The aberrant proliferation and differentiation of these cells ultimately lead to dense cell accumulations with discontinuous lumens. In NPHP knockdown planarians, cysts primarily arise in the PT at early stage, but over time, progressively affect the DT as well (Figure 6-figure supplement 2B). The severity of the cystic phenotype intimately depends on global proliferation rates (Figure 6F-J), which, interestingly, is also the case in human CKDs (Wilson and Goilav, 2007). However, not all aspects of the planarian NPHP(RNAi) phenotypes phenocopy human NPHP. In human NPHP, cysts arise at the corticomedullary junction of the kidneys, meaning that they mostly develop from the distal convoluted and collecting tubules (Hildebrandt and Zhou, 2007). This discrepancy could be due to the differential distribution of cilia, which in planarians are only present in the PT (Rink et al., 2011). Accordingly, PT cysts could be the direct consequence of cilia dysfunction, while structural alterations of the DT could be a secondary consequence of overproliferation of protonephridial progenitors. Conversely, cilia are found on the apical surface of most epithelial cells lining the human nephrons with the exception of the intercalated cells interspersed along the CD (Webber and Lee, 1975). Nevertheless, why cysts predominantly affect the distal convoluted and collecting tubules only, but not other tubule parts in human NPHP is still unknown.

\section{Conclusion}

Overall, the interplay between cilia and cell proliferation in protonephridial cyst formation is remarkably similar between humans and planarians. Therefore, in planarian protonephridia, cilia appear to generate a non-cell autonomous signal capable of regulating the proliferation of protonephridial progenitors and orchestrating their integration into the protonephridial tubules (Figure 7J). The search for the flow-regulated progenitor populations in the adult vertebrate kidneys is currently an active area of research (Elger et al., 2003; Diep et al., 2011; McCampbell and Wingert, 2012; Rinkevich et al., 2014). The mechanisms constituting the non-cell autonomous signal between tubule cells and progenitor cells is a second missing element in our current understanding of human CKDs and the homeostatic role of flow sensing in general. Given the striking evolutionary conservation of flow sensing and flow-dependent progenitor proliferation between planarians and vertebrates, it seems likely that also this elusive signal is conserved. In this regard, the high speed and low cost of high-throughput RNAi screening in planarians therefore provides a novel experimental paradigm for gene discovery and mechanistic studies of human kidney diseases.

\section{Materials and methods}

\section{Planarian maintenance and irradiation}

The CIW4 clonal line of S. mediterranea was maintained as described (Cebria and Newmark, 2005). 1 week starved animals were used for all experiments. For irradiation experiments, animals were exposed to 1250 or 6000 rads on a GammaCell 40 Exactor irradiator.

\section{Gene identification and cloning}

Human, mouse, Xenopus and zebrafish protein sequences were used to find planarian homologs from S. mediterranea genome database via TBLASTN. Planarian homologs were then used for reciprocal BLAST against the human refseq to verify the homology. All genes were cloned from an 8 day regeneration time course cDNA library prepared as described previously (Gurley et al., 2008). Primers used for cloning are described in Supplementary files 1, 4.

\section{Phylogenetic analysis}

The complete set of protein sequences were retrieved for human, mouse, and fly from Ensembl (release 76) (Flicek et al., 2014). The mosquito protein sequences were retrieved from Ensembl metazoa (release 23). Only the proteins corresponding to the longest isoform of each gene were considered for the analysis. The PFAM protein domains (PfamA-27.0) (Finn et al., 2014) were predicted for all those proteins from human, mouse, fly and mosquito and the planarian homologs of solute carriers using the InterProScan (version 5.4-47.0) tool (Jones et al., 2014). The solute carrier proteins were classified into their corresponding solute carrier family or clan groups based on the presence of the corresponding PFAM protein domain as described in the literature (He et al., 2009; 
Hoglund et al., 2011). The predicted domain regions were extracted from those proteins and multiple sequence alignment was then performed for those extracted regions using clustalw2 (version 2.1, with default parameters) (Larkin et al., 2007). Using the sequence alignment, the bootstrapped neighbor joining trees (positions with gaps removed and corrected for multiple substitution) were constructed using clustalw2 (version 2.1) (Larkin et al., 2007).

\section{In situ hybridization and immunohistochemistry}

Colorimetric and FISHs were performed as previously described (Pearson et al., 2009; King and Newmark, 2013). Following fluorescent or NBT/BCIP development, animals were incubated with anti-acetylated-Tubulin antibody (1:1000, Cell Signaling, Danvers, MA), anti-H3P (1:1000, Millipore), or a rabbit antiserum recognized unknown epitope to visualize the lumen of PT (1:500). Primary antibodies were detected with either Alexa-conjugated anti-rabbit antibodies (1:1000; Abcam) or HRP-conjugated anti-rabbit antibodies (1:1000; Jackson ImmunoResearch). NBT/BCIP developed whole-mount in situ specimens were mounted in mounting media containing $75 \%$ glycerol and $2 \mathrm{M}$ urea. Fluorescent whole-mount in situ specimens were mounted in modified ScaleA2 containing $20 \%$ glycerol, 2.5\% DABCO and $4 \mathrm{M}$ urea (Hama et al., 2011). For cryosectioning, fluorescently stained whole-mounted animals were fixed overnight in $4 \%$ paraformaldehyde (in PBS) at $4^{\circ} \mathrm{C}$, washed three times in PBS, equilibrated in 30\% sucrose, frozen in OCT, and cryosectioned (10-20 $\mu \mathrm{m})$.

\section{Imaging and image quantification}

A Leica M205 Stereo Microscope was used for documenting live images, videos, and NBT/BCIP developed whole-mount in situ specimens. Zeiss LSM-510 VIS or LSM-700 Upright confocal microscopes were used to capture fluorescent whole-mount in situ specimens and image projections. To quantify the average size of each protonephridial unit and mitotic activity, individual worm was imaged and tiled on a Perkin Elmer Ultraview spinning disk microscope. Stitching and mitotic activity quantification was performed in FiJi using standard plugins (Schindelin et al., 2012). Worm area, protonephridial size and number were measured/counted using a custom signal to noise thresholding and seeded region grow plugins. Batching was performed using macros. Movement speed quantification was performed on video sequences (acquired at $17.5 \mathrm{~Hz}$ ) using a custom thresholding plugin and Mtrack2 (Klopfenstein and Vale, 2004). For each tracked object, the initial position was subtracted from the final to determine an average translocation velocity. Average velocities were computed by weighting track averages by the length of the track. Plugins and macros are available at https://github.com/jouyun.

\section{BrdU labeling}

BrdU was administered by soaking animals in $15 \mathrm{mg} / \mathrm{ml} \mathrm{BrdU}$ and 3\% DMSO (diluted in 0.1× Montjuic salts) for $1 \mathrm{hr}$ as previously described (Cowles et al., 2012) and chasing for specified time. Animals were fixed and processed as in situ hybridization protocol except they were bleach in $6 \% \mathrm{H}_{2} \mathrm{O}_{2}$ in PBSTx (0.5\% Triton) for 3-4 hr under direct light. After in situ development, specimens were treated with $2 \mathrm{~N} \mathrm{HCl}$ for $45 \mathrm{~min}$ at room temperature, and washed four times with PBSTx (0.3\% Triton) for $1 \mathrm{hr}$. BrdU was detected using rat anti-BrdU antibody (1:1000; Abcam, Cat. No. ab6326). Primary antibody was detected with HRP-conjugated anti-rat antibody (1:1000; Jackson ImmunoResearch).

\section{Ultrafiltration and reabsorption assay}

To assay ultrafiltration capacity of planarian protonephridia, $10 \mathrm{kDa}$ tetramethylrhodamine-dextran (Molecular Probes, D-1817) and $500 \mathrm{kDa}$ fluorescein-dextran (Molecular Probes, D-7136) at the concentration of $1 \mathrm{mg} / \mathrm{ml}$ were co-injected into the mesenchyme of the animals. After $2 \mathrm{hr}$, the animals were rinsed with an excess of $1 \times$ Montjuic salts, fixed in cold $4 \%$ paraformaldehyde (in 1x Montjuic salts), mounted in modified ScaleA2 and photographed using a Zeiss LSM-510 VIS confocal microscope. Dextran uptake was quantified by measuring the average fluorescence intensity per unit area using a standard signal to noise thresholding in Fiji (Schindelin et al., 2012). For immunostaining, after fixation, the samples were rinsed 3-4 times with PBSTx (0.3\% Triton), incubated in blocking solution containing $5 \%$ horse serum in PBSTx ( $0.5 \%$ Triton) for $2 \mathrm{hr}$ at room temperature, and then in anti-acetylated-Tubulin antibody (1:1000, Cell Signaling). Primary antibody was detected using Alexaconjugated anti-rabbit antibodies (1:1000; Abcam). 


\section{$\mathrm{pH}_{\mathbf{i}}$ reporter assay}

Intracellular $\mathrm{pH}$ was measured using ratiometric $\mathrm{pH}$ dye SNARF-5F-AM (Molecular Probes, Cat. No. S-23923) at $5 \mu \mathrm{M}$ (in DMSO with 20\% wt/vol Pluronic F-127) as previously described (Beane et al., 2011, 2013). Animals were soaked for $1 \mathrm{hr}$, rinsed three times with an excess of $1 \times$ Montjuic salts, immobilized on the glass bottom dish using the microfluidic device and imaged at both $640 \mathrm{~nm}$ ( $\mathrm{pH}$ sensitive) and $580 \mathrm{~nm}$ ( $\mathrm{pH}$ insensitive) wavelengths using a LSM-700 Falcon confocal microscope. The ratio of 580/640 (used for controlling uneven dye uptake) was shown.

\section{High-speed video microscopy}

To visualize cilia beating along the lateral body edge of the planarian head region, live worms are immobilized on the glass bottom dish using a microfluidic device and imaged on a Zeiss Axiovert 200 microscope under DIC optics using $63 \times$ objective. Series of images were captured at 250 frames per second with pixel number of $800 \times 800$ (exposure time is $3.97 \mathrm{~ms}$ ) using an ORCA-Flash4.0 V2 C11440-22CU camera from Hamamatsu. Spatiotemporal image correlation spectroscopy was used to determine the speed of the cilia for each animal. In each time-lapse, 100 consecutive frames were manually selected in which the animal was stationary so that no image registration was required. A region of interest was manually drawn around the cilia in each time-lapse. The area outside this region was uniformly filled with the average intensity inside the region. Spatiotemporal correlation was then carried out in $32 \times 32$ pixel regions with a 16 pixel overlap between the regions to allow for highly localized motions to be accurately represented using the fast Fourier transform method. The average cilia displacement within the correlation image is represented by the maximum of the spatial cross-correlation between two images separated in time. The time correlation shift was a single frame, and all velocities were converted to micrometers per minute. This method was adapted from a previous paper (Yi et al., 2011), where it was implemented with custom plugins written in Java for ImageJ, available for download at (http://research.stowers.org/imagejplugins).

\section{Statistical analysis}

Statistical analysis of the data was carried out in Excel. p values were determined using Student's t-test.

\section{EM}

Specimens were prepared as following at $4^{\circ} \mathrm{C}$ on orbital rotator: (1) fix in cold $2.5 \%$ glutaraldehyde in $0.05 \mathrm{M}$ or $0.1 \mathrm{M}$ sodium cacodylate (contained $1 \mathrm{mM} \mathrm{CaCl}_{2}$ ) for overnight; (2) wash in wash buffer ( $0.1 \mathrm{M}$ sodium cacodylate buffer; $1 \mathrm{mM} \mathrm{CaCl}_{2}$; and $1 \%$ sucrose) for $1 \mathrm{hr}$ (3-4 exchanges); (3) fix in $1 \%$ Osmium tetroxide in $0.1 \mathrm{M}$ sodium cacodylate buffer $\left(+1 \mathrm{mM} \mathrm{CaCl}_{2}\right.$ ) for $2 \mathrm{hr}$; (4) wash in wash buffer for $1 \mathrm{hr}$ (3-4 exchanges) and in distill water for $30 \mathrm{~min}$ (3-4 exchanges); (5) fix in 0.5\% aqueous Uranyl Acetate (in dark) overnight; (6) wash in distill water for $30 \mathrm{~min}$ (3-4 exchanges); (7) and dehydrate in acetone 30\% (20 min), 50\% (20 min), 70\% (overnight), 90\% (20 min, 2 times), and 100\% (20 min, 3 times). Specimens were then embedded in epon-araldite or Spurr's resin as follows: $25 \%$ resin/ acetone for $3 \mathrm{hr} ; 50 \%$ resin/acetone for $2.5 \mathrm{hr} ; 75 \%$ resin/acetone overnight; $100 \%$ resin without accelerator with microwave at $350 \mathrm{~W}$ for $3 \mathrm{~min}$ on $/ 3 \mathrm{~min}$ off $/ 3 \mathrm{~min}$ on for 1 day (2 exchanges); $100 \%$ resin with accelerator with microwave at $350 \mathrm{~W}$ for $3 \mathrm{~min}$ on $/ 3 \mathrm{~min}$ off $/ 3 \mathrm{~min}$ on for 1 day (2 exchanges) and placed in $60^{\circ} \mathrm{C}$ oven for polymerization for 2 days. Ultra-thin 50-100 nm sections were collected using a Leica UC6 Ultramicrotome. TEM specimens were stained with Sato's lead (3 min)/4\% Uranyl Acetate in 70\% methanol (4 min)/Sato's lead (6 min) prior to imaging on a FEI Technai BioTwin at 80 kV equipped with a Gatan UltraScan 1000 digital camera.

\section{RNAi via dsRNA feeding}

RNAi feedings were performed as described previously (Gurley et al., 2008; Rink et al., 2009). Feeding and amputation schedules were tailored for each experiment and described in detail as following:

Figure 3C: 5 dsRNA feedings (3 days in between).

Figure 4C,D, Figure 4-figure supplement 2A: 8 dsRNA feedings (3 days in between).

Figure 4E,F: 9 dsRNA feedings (3 days in between).

Figure 4-figure supplement 2B, Figure 4-figure supplement 3: 6 dsRNA feedings (3 days in between) prior to amputation.

Figure 5A-C: 3 dsRNA feedings (3 days in between). 
Figure 6, Figure 6-figure supplement 1C-E, Figure 6-figure supplement 2C, Figure 6-figure supplement 3: 2 dsRNA feedings (3 days in between).

Figure 7A-C: 3 dsRNA feedings (2 days in between).

Figure 7D-I, Figure 7-figure supplement 1A: IFT88- and LRRC50(RNAi): 3 dsRNA feedings ( 2 days in between); DNAH $\beta$-1(RNAi): 8 dsRNA feedings (2 days in between).

\section{Acknowledgements}

We thank Jeffrey Lange and Aurimas Gumbrys for the planarian immobilization method using microfluidic devices, Jeffrey Lange and Zulin Yu for live imaging assistance, Eric Ross for bioinformatics assistance, and all member of the Sánchez lab, especially Li-chun Cheng and Sarah Elliott, for technical advice and critical suggestions. We also acknowledge all members of the Histology, Microscopy, Molecular Biology, and Reptile \& Aquatics core facilities at the Stowers Institute for Medical Research for their technical support. This work was supported by NIH R37GM057260 to ASA. HTV is a Vietnam Education Foundation Fellow. ASA is an investigator of the Howard Hughes Medical Institute and an investigator of the Stowers Institute for Medical Research.

\section{Additional information}

Competing interests

ASA: Reviewing editor, eLife. The other authors declare that no competing interests exist.

Funding

\begin{tabular}{lll} 
Funder & Grant reference & Author \\
\hline National Institutes of Health (NIH) & R37GM057260 & Alejandro Sánchez Alvarado \\
\hline $\begin{array}{l}\text { Howard Hughes Medical Institute } \\
\text { (HHMI) }\end{array}$ & Investigator & Alejandro Sánchez Alvarado \\
\hline
\end{tabular}

The funders had no role in study design, data collection and interpretation, or the decision to submit the work for publication.

Author contributions

HT-KV, Conception and design, Acquisition of data, Analysis and interpretation of data, Drafting or revising the article; JCR, ASA, Conception and design, Analysis and interpretation of data, Drafting or revising the article; SAMK, Analysis and interpretation of data; MMC, Acquisition of data, Analysis and interpretation of data; NL, Carried out phylogenetic analysis for the planarian solute carriers; RA, Performed STICS analysis

\section{Additional files}

Supplementary files

- Supplementary file 1. Summary information of the planarian homologs of slc genes.

DOI: 10.7554/eLife.07405.049

- Supplementary file 2. Expression domains of slc genes in the planarian protonephridia.

DOI: 10.7554/eLife.07405.050

- Supplementary file 3. Expression domains of slc genes in the rodent metanephros.

DOI: $10.7554 /$ LLife.07405.051

- Supplementary file 4. Summary information of the planarian homologs of human kidney disease genes.

DOI: 10.7554/eLife.07405.052

\section{References}

Adler CE, Seidel CW, McKinney SA, Sanchez Alvarado A. 2014. Selective amputation of the pharynx identifies a foxa-dependent regeneration program in planaria. eLife 3:e02238. doi: 10.7554/eLife.02238.

Azimzadeh J, Wong ML, Downhour DM, Sanchez Alvarado A, Marshall WF. 2012. Centrosome loss in the evolution of planarians. Science 335:461-463. doi: 10.1126/science.1214457. 
Badano JL, Mitsuma N, Beales PL, Katsanis N. 2006. The ciliopathies: an emerging class of human genetic disorders. Annual Review of Genomics and Human Genetics 7:125-148. doi: 10.1146/annurev.genom.7.080505.115610.

Bagga A, Vasudev A, Kabra SK, Mukhopadhyay S, Bhuyan UN, Srivastava R. 1989. Nephronophthisis with bronchiectasis. Child Nephrology and Urology 10:211-213.

Beane WS, Morokuma J, Adams DS, Levin M. 2011. A chemical genetics approach reveals h,k-atpase-mediated membrane voltage is required for planarian head regeneration. Chemistry \& Biology 18:77-89. doi: 10.1016/j. chembiol.2010.11.012.

Beane WS, Morokuma J, Lemire JM, Levin M. 2013. Bioelectric signaling regulates head and organ size during planarian regeneration. Development 140:313-322. doi: 10.1242/dev.086900.

Bergmann C, Fliegauf M, Brüchle NO, Frank V, Olbrich H, Kirschner J, Schermer B, Schmedding I, Kispert A, Kränzlin B, Nürnberg G, Becker C, Grimm T, Girschick G, Lynch SA, Kelehan P, Senderek J, Neuhaus TJ, Stallmach T, Zentgraf H, Nürnberg P, Gretz N, Lo C, Lienkamp S, Schäfer T, Walz G, Benzing T, Zerres K, Omran H. 2008. Loss of nephrocystin-3 function can cause embryonic lethality, meckel-gruber-like syndrome, situs inversus, and renal-hepatic-pancreatic dysplasia. American Journal of Human Genetics 82:959-970. doi: 10.1016/ j.ajhg.2008.02.017.

Betleja E, Cole DG. 2010. Ciliary trafficking: Cep290 guards a gated community. Current Biology 20:R928-R931. doi: 10.1016/j.cub.2010.09.058.

Bisceglia M, Galliani CA, Senger C, Stallone C, Sessa A. 2006. Renal cystic diseases: a review. Advances in Anatomic Pathology 13:26-56. doi: 10.1097/01.pap.0000201831.77472.d3.

Buechner M. 2002. Tubes and the single C. elegans excretory cell. Trends in Cell Biology 12:479-484. doi: 10. 1016/S0962-8924(02)02364-4.

Carraro-Lacroix LR, Malnic G. 2010. Acid-base transport by the renal distal nephron. Journal of Nephrology 23 (Suppl 16):S19-S27.

Cebria F, Newmark PA. 2005. Planarian homologs of netrin and netrin receptor are required for proper regeneration of the central nervous system and the maintenance of nervous system architecture. Development 132:3691-3703. doi: 10.1242/dev.01941.

Cowles MW, Brown DD, Nisperos SV, Stanley BN, Pearson BJ, Zayas RM. 2013. Genome-wide analysis of the bhlh gene family in planarians identifies factors required for adult neurogenesis and neuronal regeneration. Development 140:4691-4702. doi: 10.1242/dev.098616.

Cowles MW, Hubert A, Zayas RM. 2012. A lissencephaly-1 homologue is essential for mitotic progression in the planarian Schmidtea mediterranea. Developmental Dynamics 241:901-910. doi: 10.1002/dvdy.23775.

Craige B, Tsao CC, Diener DR, Hou Y, Lechtreck KF, Rosenbaum JL, Witman GB. 2010. Cep290 tethers flagellar transition zone microtubules to the membrane and regulates flagellar protein content. The Journal of Cell Biology 190:927-940. doi: 10.1083/jcb.201006105.

Deane JA, Ricardo SD. 2012. Emerging roles for renal primary cilia in epithelial repair. International Review of Cell and Molecular Biology 293:169-193. doi: 10.1016/B978-0-12-394304-0.00011-7.

Diep CQ, Ma D, Deo RC, Holm TM, Naylor RW, Arora N, Wingert RA, Bollig F, Djordjevic G, Lichman B, Zhu H, Ikenaga T, Ono F, Englert C, Cowan CA, Hukriede NA, Handin RI, Davidson AJ. 2011. Identification of adult nephron progenitors capable of kidney regeneration in zebrafish. Nature 470:95-100. doi: 10.1038/nature09669.

Donoviel DB, Freed DD, Vogel H, Potter DG, Hawkins E, Barrish JP, Mathur BN, Turner CA, Geske R, Montgomery CA, Starbuck M, Brandt M, Gupta A, Ramirez-Solis R, Zambrowicz BP, Powell DR. 2001. Proteinuria and perinatal lethality in mice lacking neph1, a novel protein with homology to nephrin. Molecular and Cellular Biology 21 4829-4836. doi: 10.1128/MCB.21.14.4829-4836.2001.

Dow JA, Romero MF. 2010. Drosophila provides rapid modeling of renal development, function, and disease. American journal of physiology. Renal Physiology 299:F1237-F1244. doi: 10.1152/ajprenal.00521.2010.

Driscoll JA, Bhalla S, Liapis H, Ibricevic A, Brody SL. 2008. Autosomal dominant polycystic kidney disease is associated with an increased prevalence of radiographic bronchiectasis. Chest 133:1181-1188. doi: 10.1378/ chest.07-2147.

Drummond IA. 2005. Kidney development and disease in the zebrafish. Journal of the American Society of Nephrology 16:299-304. doi: 10.1681/ASN.2004090754.

Ebarasi L, Oddsson A, Hultenby K, Betsholtz C, Tryggvason K. 2011. Zebrafish: a model system for the study of vertebrate renal development, function, and pathophysiology. Current Opinion in Nephrology and Hypertension 20:416-424. doi: 10.1097/MNH.0b013e3283477797.

Eley L, Yates LM, Goodship JA. 2005. Cilia and disease. Current Opinion in Genetics \& Development 15:308-314. doi: 10.1016/j.gde.2005.04.008.

Elger M, Hentschel H, Litteral J, Wellner M, Kirsch T, Luft FC, Haller H. 2003. Nephrogenesis is induced by partial nephrectomy in the elasmobranch leucoraja erinacea. Journal of the American Society of Nephrology 14: 1506-1518. doi: 10.1097/01.ASN.0000067645.49562.09.

Ferkol TW, Leigh MW. 2012. Ciliopathies: the central role of cilia in a spectrum of pediatric disorders. The Journal of Pediatrics 160:366-371. doi: 10.1016/j.jpeds.2011.11.024.

Finn RD, Bateman A, Clements J, Coggill P, Eberhardt RY, Eddy SR, Heger A, Hetherington K, Holm L, Mistry J, Sonnhammer EL, Tate J, Punta M. 2014. Pfam: the protein families database. Nucleic Acids Research 42: D222-D230. doi: 10.1093/nar/gkt1223.

Flicek P, Amode MR, Barrell D, Beal K, Billis K, Brent S, Carvalho-Silva D, Clapham P, Coates G, Fitzgerald S, Gil L, Girón CG, Gordon L, Hourlier T, Hunt S, Johnson N, Juettemann T, Kähäri AK, Keenan S, Kulesha E, Martin FJ, Maurel T, McLaren WM, Murphy DN, Nag R, Overduin B, Pignatelli M, Pritchard B, Pritchard E, Riat HS, Ruffier M, Sheppard D, Taylor K, Thormann A, Trevanion SJ, Vullo A, Wilder SP, Wilson M, Zadissa A, Aken BL, Birney E, 
Cunningham F, Harrow J, Herrero J, Hubbard TJ, Kinsella R, Muffato M, Parker A, Spudich G, Yates A, Zerbino DR, Searle SM. 2014. Ensembl 2014. Nucleic Acids Research 42:D749-D755. doi: 10.1093/nar/gkt1196.

Fliegauf M, Horvath J, von Schnakenburg C, Olbrich H, Muller D, Thumfart J, Schermer B, Pazour GJ, Neumann HP, Zentgraf H, Benzing T, Omran H. 2006. Nephrocystin specifically localizes to the transition zone of renal and respiratory cilia and photoreceptor connecting cilia. Journal of the American Society of Nephrology 17: 2424-2433. doi: 10.1681/ASN.2005121351.

Furness P, Hall L, Shaw J, Pringle J. 1999. Glomerular expression of nephrin is decreased in acquired human nephrotic syndrome. Nephrology, Dialysis, Transplantation 14:1234-1237. doi: 10.1093/ndt/14.5.1234.

Glazer AM, Wilkinson AW, Backer CB, Lapan SW, Gutzman JH, Cheeseman IM, Reddien PW. 2010. The zn finger protein iguana impacts hedgehog signaling by promoting ciliogenesis. Developmental Biology 337:148-156. doi: 10.1016/j.ydbio.2009.10.025.

Gurley KA, Rink JC, Sanchez Alvarado A. 2008. Beta-catenin defines head versus tail identity during planarian regeneration and homeostasis. Science 319:323-327. doi: 10.1126/science.1150029.

Haeckel E. 1866. General morphology of organisms: general features of the science of organic form, mechanically based on the descendancy theory as revised by charles darwin (Berlin: Georg Riemer)

Hama H, Kurokawa H, Kawano H, Ando R, Shimogori T, Noda H, Fukami K, Sakaue-Sawano A, Miyawaki A. 2011. Scale: a chemical approach for fluorescence imaging and reconstruction of transparent mouse brain. Nature Neuroscience 14:1481-1488. doi: 10.1038/nn.2928.

Hassan MO, Subramanyan S. 1995. Ciliated renal tubular cells in crescentic glomerulonephritis. Ultrastructural Pathology 19:201-203. doi: 10.3109/01913129509064222.

He L, Vasiliou K, Nebert DW. 2009. Analysis and update of the human solute carrier (slc) gene superfamily. Human Genomics 3:195-206. doi: 10.1186/1479-7364-3-2-195.

Hildebrandt F, Otto E. 2000. Molecular genetics of nephronophthisis and medullary cystic kidney disease. Journal of the American Society of Nephrology 11:1753-1761.

Hildebrandt F, Otto E. 2005. Cilia and centrosomes: a unifying pathogenic concept for cystic kidney disease? Nature Reviews. Genetics 6:928-940. doi: 10.1038/nrg1727.

Hildebrandt F, Zhou W. 2007. Nephronophthisis-associated ciliopathies. Journal of the American Society of Nephrology 18:1855-1871. doi: 10.1681/ASN.2006121344.

Hoglund PJ, Nordstrom KJ, Schioth HB, Fredriksson R. 2011. The solute carrier families have a remarkably long evolutionary history with the majority of the human families present before divergence of bilaterian species. Molecular Biology and Evolution 28:1531-1541. doi: 10.1093/molbev/msq350.

Igarashi P. 2005. Overview: nonmammalian organisms for studies of kidney development and disease. Journal of the American Society of Nephrology 16:296-298. doi: 10.1681/ASN.2004110951.

Ishii S. 1980a. The ultrastructure of the protonephridial flame cell of the freshwater planarian bdellocephala brunnea. Cell and Tissue Research 206:441-449.

Ishii S. 1980b. The ultrastructure of the protonephridial tubules of the freshwater planarian bdellocephala brunnea. Cell and tissue research 206:451-458.

Jones P, Binns D, Chang HY, Fraser M, Li W, McAnulla C, McWilliam H, Maslen J, Mitchell A, Nuka G, Pesseat S, Quinn AF, Sangrador-Vegas A, Scheremetjew M, Yong SY, Lopez R, Hunter S. 2014. Interproscan 5: genomescale protein function classification. Bioinformatics 30:1236-1240. doi: 10.1093/bioinformatics/btu031.

Kang H, Sanchez Alvarado A. 2009. Flow cytometry methods for the study of cell-cycle parameters of planarian stem cells. Developmental Dynamics 238:1111-1117. doi: 10.1002/dvdy.21928.

Kartagener M, Horlacher A. 1935. Bronchiektasien bei situs viscerum inversus. Schweizerische Medizinische Wochenschrift 65:782-784.

Katz SM, Morgan JJ. 1984. Cilia in the human kidney. Ultrastructural pathology 6:285-294. doi: 10.3109/ 01913128409018587.

Kestila M, Lenkkeri U, Mannikko M, Lamerdin J, McCready P, Putaala H, Ruotsalainen V, Morita T, Nissinen M, Herva R, Kashtan CE, Peltonen L, Holmberg C, Olsen A, Tryggvason K. 1998. Positionally cloned gene for a novel glomerular protein-nephrin-is mutated in congenital nephrotic syndrome. Molecular Cell 1:575-582. doi: 10 1016/S1097-2765(00)80057-X.

King RS, Newmark PA. 2013. In situ hybridization protocol for enhanced detection of gene expression in the planarian Schmidtea mediterranea. BMC Developmental Biology 13:8. doi: 10.1186/1471-213X-13-8.

Kinugasa S, Tojo A, Sakai T, Tsumura H, Takahashi M, Hirata Y, Fujita T. 2011. Selective albuminuria via podocyte albumin transport in puromycin nephrotic rats is attenuated by an inhibitor of nadph oxidase. Kidney International 80:1328-1338. doi: 10.1038/ki.2011.282.

Klopfenstein DR, Vale RD. 2004. The lipid binding pleckstrin homology domain in unc-104 kinesin is necessary for synaptic vesicle transport in Caenorhabditis elegans. Molecular Biology of the Cell 15:3729-3739. doi: 10.1091/ mbc.E04-04-0326.

Kotsis F, Boehlke C, Kuehn EW. 2013. The ciliary flow sensor and polycystic kidney disease. Nephrology, Dialysis, Transplantation 28:518-526. doi: 10.1093/ndt/gfs524.

Kramer-Zucker AG, Olale F, Haycraft CJ, Yoder BK, Schier AF, Drummond IA. 2005. Cilia-driven fluid flow in the zebrafish pronephros, brain and kupffer's vesicle is required for normal organogenesis. Development 132 1907-1921. doi: 10.1242/dev.01772.

Lacy ER, Luciano L, Reale E. 1989. Flagellar cells and ciliary cells in the renal tubule of elasmobranchs. Supplement: published under auspices of the American Society of Zoologists and the Division of Comparative Physiology and Biochemistry/The Wistar Institute of Anatomy and Biology. The Journal of Experimental Zoology 2:186-192. doi: 10.1002/jez.1402520420. 
Lahdenkari AT, Lounatmaa K, Patrakka J, Holmberg C, Wartiovaara J, Kestila M, Koskimies O, Jalanko H. 2004. Podocytes are firmly attached to glomerular basement membrane in kidneys with heavy proteinuria. Journal of the American Society of Nephrology 15:2611-2618. doi: 10.1097/01.ASN.0000139478.03463.D9.

Landowski C. 2008. The mammalian transporter families. In: Hebert RAAS, editor. Seldin and giebisch's the kidney. 4th edition, Academic Press. p. 91-146.

Larkin MA, Blackshields G, Brown NP, Chenna R, McGettigan PA, McWilliam H, Valentin F, Wallace IM, Wilm A, Lopez R, Thompson JD, Gibson TJ, Higgins DG. 2007. Clustal w and clustal x version 2.0. Bioinformatics 23 : 2947-2948. doi: 10.1093/bioinformatics/btm404.

Lodi D, Ligabue G, Lupo V, Cavazzini F. 2012. The role of pec progenitors in adpkd progression. International Journal of Stem Cells 5:65-72. doi: 10.15283/ijsc.2012.5.1.65.

Marshall EK Jr. 1934. The comparative physiology of the kidney in relation to theories of renal secretion. Physiological Reviews 14:133-159.

McCampbell KK, Wingert RA. 2012. Renal stem cells: fact or science fiction? The Biochemical Journal 444: 153-168. doi: 10.1042/BJ20120176.

McKanna JA. 1968a. Fine structure of the protonephridial system in Planaria. I. Flame cells. Zeitschrift fur Zellforschung und mikroskopische Anatomie 92:509-523. doi: 10.1007/BF00336662.

McKanna JA. 1968b. Fine structure of the protonephridial system in Planaria. li. Ductules, collecting ducts, and osmoregulatory cells. Zeitschrift fur Zellforschung und mikroskopische Anatomie 92:524-535. doi: 10.1007/ BF00336663.

Moalem S, Keating S, Shannon P, Thompson M, Millar K, Nykamp K, Forster A, Noor A, Chitayat D. 2013. Broadening the ciliopathy spectrum: motile cilia dyskinesia, and nephronophthisis associated with a previously unreported homozygous mutation in the invs/nphp2 gene. American Journal of Medical Genetics Part A 161A: 1792-1796. doi: 10.1002/ajmg.a.36036.

Mollet G, Silbermann F, Delous M, Salomon R, Antignac C, Saunier S. 2005. Characterization of the nephrocystin/ nephrocystin-4 complex and subcellular localization of nephrocystin-4 to primary cilia and centrosomes. Human Molecular Genetics 14:645-656. doi: 10.1093/hmg/ddi061.

Moore A, Escudier E, Roger G, Tamalet A, Pelosse B, Marlin S, Clement A, Geremek M, Delaisi B, Bridoux AM, Coste A, Witt M, Duriez B, Amselem S. 2006. Rpgr is mutated in patients with a complex $x$ linked phenotype combining primary ciliary dyskinesia and retinitis pigmentosa. Journal of Medical Genetics 43:326-333. doi: 10. 1136/jmg.2005.034868.

Moua T, Zand L, Hartman RP, Hartman TE, Qin D, Peikert T, Qian Q. 2014. Radiologic and clinical bronchiectasis associated with autosomal dominant polycystic kidney disease. PLOS ONE 9:e93674. doi: 10.1371/journal.pone. 0093674.

Murer L, Caridi G, Della Vella M, Montini G, Carasi C, Ghiggeri G, Zacchello G. 2002. Expression of nuclear transcription factor pax2 in renal biopsies of juvenile nephronophthisis. Nephron 91:588-593. doi: 10.1159/ 000065017.

Nauli SM, Alenghat FJ, Luo Y, Williams E, Vassilev P, Li X, Elia AE, Lu W, Brown EM, Quinn SJ, Ingber DE, Zhou J. 2003. Polycystins 1 and 2 mediate mechanosensation in the primary cilium of kidney cells. Nature Genetics 33: 129-137. doi: 10.1038/ng1076.

Nielsen S, Frokiaer J, Marples D, Kwon TH, Agre P, Knepper MA. 2002. Aquaporins in the kidney: from molecules to medicine. Physiological Reviews 82:205-244. doi: 10.1152/physrev.00024.2001.

Omran H. 2010. Nphp proteins: gatekeepers of the ciliary compartment. The Journal of Cell Biology 190:715-717. doi: $10.1083 /$ jcb.201008080.

Pannabecker TL. 2012. Structure and function of the thin limbs of the loop of henle. Comprehensive Physiology 2: 2063-2086. doi: 10.1002/cphy.c110019.

Pavenstadt H, Kriz W, Kretzler M. 2003. Cell biology of the glomerular podocyte. Physiological Reviews 83: 253-307. doi: 10.1152/physrev.00020.2002.

Pearson BJ, Eisenhoffer GT, Gurley KA, Rink JC, Miller DE, Sanchez Alvarado A. 2009. Formaldehyde-based whole-mount in situ hybridization method for planarians. Developmental Dynamics 238:443-450. doi: 10.1002/ dvdy.21849.

Pontin RM. 1964. A comparative account of the protonephridia of asplanghna (rotifera) with special reference to the flame bulbs. Proceedings of the Zoological Society of London 142:511-525. doi: 10.1111/j.1469-7998.1964. tb04511.x.

Praetorius HA, Praetorius J, Nielsen S, Frokiaer J, Spring KR. 2004. Beta1-integrins in the primary cilium of mdck cells potentiate fibronectin-induced ca2+ signaling. American Journal of Physiology. Renal Physiology 287: F969-F978. doi: 10.1152/ajprenal.00096.2004.

Praetorius HA, Spring KR. 2001. Bending the mdck cell primary cilium increases intracellular calcium. The Journal of Membrane Biology 184:71-79. doi: 10.1007/s00232-001-0075-4.

Praetorius HA, Spring KR. 2003. The renal cell primary cilium functions as a flow sensor. Current Opinion in Nephrology and Hypertension 12:517-520. doi: 10.1097/01.mnh.0000088730.87142.d1.

Priolo C, Henske EP. 2013. Metabolic reprogramming in polycystic kidney disease. Nature Medicine 19:407-409. doi: $10.1038 / \mathrm{nm} .3140$.

Quarmby LM, Leroux MR. 2010. Sensorium: the original raison d'etre of the motile cilium? Journal of Molecular Cell Biology 2:65-67. doi: 10.1093/jmcb/mjp036.

Raciti D, Reggiani L, Geffers L, Jiang Q, Bacchion F, Subrizi AE, Clements D, Tindal C, Davidson DR, Kaissling B, Brändli AW. 2008. Organization of the pronephric kidney revealed by large-scale gene expression mapping. Genome Biology 9:R84. doi: 10.1186/gb-2008-9-5-r84. 
Rink JC. 2013. Stem cell systems and regeneration in Planaria. Development Genes and Evolution 223:67-84. doi: 10.1007/s00427-012-0426-4.

Rink JC, Gurley KA, Elliott SA, Sanchez Alvarado A. 2009. Planarian hh signaling regulates regeneration polarity and links hh pathway evolution to cilia. Science 326:1406-1410. doi: 10.1126/science.1178712.

Rink JC, Vu HT, Sanchez Alvarado A. 2011. The maintenance and regeneration of the planarian excretory system are regulated by egfr signaling. Development 138:3769-3780. doi: 10.1242/dev.066852.

Rinkevich Y, Montoro DT, Contreras-Trujillo H, Harari-Steinberg O, Newman AM, Tsai JM, Lim X, Van-Amerongen R, Bowman A, Januszyk M, Pleniceanu O, Nusse R, Longaker MT, Weissman IL, Dekel B. 2014. In vivo clonal analysis reveals lineage-restricted progenitor characteristics in mammalian kidney development, maintenance, and regeneration. Cell Reports 7:1270-1283. doi: 10.1016/j.celrep.2014.04.018.

Ruppert EE. 1994. Evolutionary origin of the vertebrate nephron. American Zoologist 34:542-553.

Ruppert EE, Smith PR. 1988. The functional organization of filtration nephridia. Biological Reviews 63:231-258. doi: 10.1111/j.1469-185X.1988.tb00631.x.

Saeki H, Kondo S, Morita T, Sasagawa I, Ishizuka G, Koizumi Y. 1984. Immotile cilia syndrome associated with polycystic kidney. The Journal of Urology 132:1165-1166.

Salomon R, Saunier S, Niaudet P. 2009. Nephronophthisis. Pediatric Nephrology 24:2333-2344. doi: 10.1007/ s00467-008-0840-z.

Schindelin J, Arganda-Carreras I, Frise E, Kaynig V, Longair M, Pietzsch T, Preibisch S, Rueden C, Saalfeld S, Schmid B, Tinevez JY, White DJ, Hartenstein V, Eliceiri K, Tomancak P, Cardona A. 2012. Fiji: an open-source platform for biological-image analysis. Nature Methods 9:676-682. doi: 10.1038/nmeth.2019.

Schwartz EA, Leonard ML, Bizios R, Bowser SS. 1997. Analysis and modeling of the primary cilium bending response to fluid shear. The American Journal of Physiology 272:F132-F138.

Scimone ML, Kravarik KM, Lapan SW, Reddien PW. 2014. Neoblast specialization in regeneration of the planarian Schmidtea mediterranea. Stem Cell Reports 3:339-352. doi: 10.1016/j.stemcr.2014.06.001.

Scimone ML, Srivastava M, Bell GW, Reddien PW. 2011. A regulatory program for excretory system regeneration in planarians. Development 138:4387-4398. doi: 10.1242/dev.068098.

Shah AS, Ben-Shahar Y, Moninger TO, Kline JN, Welsh MJ. 2009. Motile cilia of human airway epithelia are chemosensory. Science 325:1131-1134. doi: 10.1126/science.1173869.

Takeda S, Narita K. 2012. Structure and function of vertebrate cilia, towards a new taxonomy. Differentiation; Research in Biological Diversity 83:S4-S11. doi: 10.1016/j.diff.2011.11.002.

Teilmann SC, Christensen ST. 2005. Localization of the angiopoietin receptors tie-1 and tie-2 on the primary cilia in the female reproductive organs. Cell Biology International 29:340-346. doi: 10.1016/j.cellbi.2005.03.006.

Tojo A, Kinugasa S. 2012. Mechanisms of glomerular albumin filtration and tubular reabsorption. International Journal of Nephrology 2012:481520. doi: 10.1155/2012/481520.

Tojo A, Onozato ML, Kitiyakara C, Kinugasa S, Fukuda S, Sakai T, Fujita T. 2008. Glomerular albumin filtration through podocyte cell body in puromycin aminonucleoside nephrotic rat. Medical Molecular Morphology 41: 92-98. doi: 10.1007/s00795-008-0397-8.

Uhlenhaut NH, Treier M. 2008. Transcriptional regulators in kidney disease: gatekeepers of renal homeostasis. Trends in Genetics 24:361-371. doi: 10.1016/j.tig.2008.05.001.

van Wolfswinkel JC, Wagner DE, Reddien PW. 2014. Single-cell analysis reveals functionally distinct classes within the planarian stem cell compartment. Cell Stem Cell 15:326-339. doi: 10.1016/j.stem.2014.06.007.

Wagner DE, Ho JJ, Reddien PW. 2012. Genetic regulators of a pluripotent adult stem cell system in planarians identified by rnai and clonal analysis. Cell Stem Cell 10:299-311. doi: 10.1016/j.stem.2012.01.016.

Wagner DE, Wang IE, Reddien PW. 2011. Clonogenic neoblasts are pluripotent adult stem cells that underlie planarian regeneration. Science 332:811-816. doi: 10.1126/science.1203983.

Warner FD. 1969. The fine structure of the protonephridia in the rotifer asplanchna. Journal of Ultrastructure Research 29:499-524. doi: 10.1016/S0022-5320(69)90070-7.

Watnick T, Germino G. 2003. From cilia to cyst. Nature Genetics 34:355-356. doi: 10.1038/ng0803-355.

Weavers H, Prieto-Sanchez S, Grawe F, Garcia-Lopez A, Artero R, Wilsch-Brauninger M, Ruiz-Gomez M, Skaer H, Denholm B. 2009. The insect nephrocyte is a podocyte-like cell with a filtration slit diaphragm. Nature 457: 322-327. doi: 10.1038/nature07526.

Webber WA, Lee J. 1975. Fine structure of mammalian renal cilia. The Anatomical Record 182:339-343. doi: 10. 1002/ar.1091820307.

Weimbs T. 2007. Polycystic kidney disease and renal injury repair: common pathways, fluid flow, and the function of polycystin-1. American Journal of Physiology. Renal Physiology 293:F1423-F1432. doi: 10.1152/ajprenal. 00275.2007.

Wenemoser D, Lapan SW, Wilkinson AW, Bell GW, Reddien PW. 2012. A molecular wound response program associated with regeneration initiation in planarians. Genes \& Development 26:988-1002. doi: 10.1101/gad. 187377.112.

White HL. 1929. Some measurements of ciliary activity. American Journal of Physiology 88:282-285.

Wilhelmi J. 1906. Untersuchungen über die excretionsorgane der sübwassertricladen. Zeitschrift für wissenschartliche Zoologie 80:544-575.

Williams CL, Li C, Kida K, Inglis PN, Mohan S, Semenec L, Bialas NJ, Stupay RM, Chen N, Blacque OE, Yoder BK, Leroux MR. 2011. Mks and nphp modules cooperate to establish basal body/transition zone membrane associations and ciliary gate function during ciliogenesis. The Journal of Cell Biology 192:1023-1041. doi: 10. 1083/jcb.201012116. 
Wilson PD. 2004a. Polycystic kidney disease. The New England Journal of Medicine 350:151-164. doi: 10.1056/ NEJMra022161.

Wilson PD. 2004b. Polycystic kidney disease: new understanding in the pathogenesis. The International Journal of Biochemistry \& Cell Biology 36:1868-1873. doi: 10.1016/j.biocel.2004.03.012.

Wilson PD. 2011. Molecular mechanisms of polycystic kidney disease. Biochimica et Biophysica Acta 1812:1201. doi: 10.1016/j.bbadis.2011.08.004.

Wilson PD, Goilav B. 2007. Cystic disease of the kidney. Annual Review of Pathology 2:341-368. doi: 10.1146/ annurev. pathol.2.010506.091850.

Wilson RA, Webster LA. 1974. Protonephridia. Biological Reviews of the Cambridge Philosophical Society 49: 127-160. doi: 10.1111/j.1469-185X.1974.tb01572.x.

Wingert RA, Davidson AJ. 2008. The zebrafish pronephros: a model to study nephron segmentation. Kidney International 73:1120-1127. doi: 10.1038/ki.2008.37.

Winyard P, Jenkins D. 2011. Putative roles of cilia in polycystic kidney disease. Biochimica et Biophysica Acta 1812: 1256-1262. doi: 10.1016/j.bbadis.2011.04.012.

Wolf MT. 2015. Nephronophthisis and related syndromes. Current Opinion in Pediatrics 27:201-211. doi: 10.1097/ MOP.0000000000000194.

Yi K, Unruh JR, Deng M, Slaughter BD, Rubinstein B, Li R. 2011. Dynamic maintenance of asymmetric meiotic spindle position through arp2/3-complex-driven cytoplasmic streaming in mouse oocytes. Nature Cell Biology 13:1252-1258. doi: 10.1038/ncb2320.

Yoder BK, Hou X, Guay-Woodford LM. 2002. The polycystic kidney disease proteins, polycystin-1, polycystin-2, polaris, and cystin, are co-localized in renal cilia. Journal of the American Society of Nephrology 13:2508-2516. doi: 10.1097/01.ASN.0000029587.47950.25.

Zhuang S, Shao H, Guo F, Trimble R, Pearce E, Abmayr SM. 2009. Sns and kirre, the Drosophila orthologs of nephrin and neph1, direct adhesion, fusion and formation of a slit diaphragm-like structure in insect nephrocytes. Development 136:2335-2344. doi: 10.1242/dev.031609.

Zimmermann HD. 1971. Cilia in the fetal kidney of man. Beiträge zur Pathologie 143:227-240. 